\title{
Medindo o acesso à Justiça Cível no Brasil
}

\author{
Fabiana Luci de Oliveira \\ Luciana Gross Cunha
}

\section{Introdução}

Acesso à justiça é um fenômeno complexo e multifacetado, constituído de diferentes dimensões e significados. Nosso objetivo neste artigo é mapear as formas como esse acesso vem sendo abordado e mensurado no Brasil, privilegiando a dimensão da vivência de conflitos, a identificação dos tipos de conflitos mais frequentes e as formas de gestão e resolução adotadas, com atenção especial para a procura ou não pelas instituições formais de justiça - sobretudo o Poder Judiciário, mas considerando também a Defensoria Pública, o Ministério Público e a Polícia, além de outros caminhos institucionais extrajudiciais, como a Fundação de Proteção e Defesa do Consumidor (Procon).

Aqui não nos interessa discutir estatísticas judiciais, como quantidade e localização de equipamentos e operadores de justiça, número de processos, taxas de litigância, entre outros indicadores objetivos utilizados para discutir acesso à justiça ${ }^{1}$ aspectos esses cobertos por dados institucionais de tribunais e especialmente pela publicação do CNJ "Justiça em Números"2, e mais recentemente pelo "Atlas de Acesso à Justiça", publicado pelo Ministério da Justiça $(2013,2014)^{3}$.

O que buscamos são formas de mensuração que visam entender a experiência das pessoas com a vivência de conflitos potencialmente jurídicos, atentando para a demanda por equipamentos de justiça e o uso destes em sua vida cotidiana, como forma de gestão desses conflitos. Assim, nosso interesse está em indicadores subjetivos de acesso à justiça, produzidos via survey.

Os indicadores subjetivos de acesso à justiça podem ser classificados em dois grandes blocos: os indicadores de comportamento (ou seja, se as pessoas vivenciaram eventos passíveis de resolução via justiça, quais foram eles e como lidaram com esses eventos) e os indicadores de percepção, valores e atitudes (ou seja, o quanto as pessoas confiam nesse sistema, quão justo acreditam que ele seja e qual sua predisposição para

\footnotetext{
${ }^{1}$ Para um mapeamento das estatísticas nacionais sobre o sistema de justiça brasileiro, ver Sadek e Oliveira (2012).

2 As 11 edições referentes aos anos de 2003 a 2013 estão disponíveis em: <http://www.cnj.jus.br/programas-e-acoes/pj-justica-em-numeros>. Acesso em: 20 ago. 2015.

${ }^{3}$ As edições podem ser encontradas no portal <http://www.acessoajustica.gov.br/pub/>. Acesso em: 20 ago. 2015.
} 
MEDINDO O ACESSO À JUSTIÇA CÍVEL NO BRASIL

utilizar o sistema quando vivenciam conflitos). Nossa análise lida apenas com indicadores de comportamento, e nosso interesse está nos eventos passíveis de resolução via Justiça Cível.

Iniciamos recuperando definições e entendimentos de acesso à justiça e aspectos teórico-metodológicos que informam surveys conduzidos em contextos internacionais que buscaram mensurar esse acesso (via indicadores subjetivos de comportamento), discutindo o que vem sendo medido e como essas medidas são realizadas, destacando os desafios postos às pesquisas futuras.

Na sequência, observamos detidamente o contexto brasileiro, a partir do principal esforço de produção desse tipo de indicadores, via IBGE, no suplemento "Vitimização e Justiça" (PNAD, 2009), e apresentamos uma proposta de mensuração que se baseia na combinação de elementos da metodologia de eventos judicializáveis (Genn, 1999) e elementos da metodologia de processamento de disputas (Felstiner, Abel e Sarat, 1980), duas abordagens que informam atualmente a maioria das pesquisas norte-americanas e europeias nessa temática, mas levando em conta as especificidades do contexto brasileiro.

\section{Contextualizando o campo de mensuração de acesso à Justiça Cível: definições e entendimentos}

Os esforços de mensuração de acesso à justiça têm como marco inaugural a década de 1970 com o Florence Project, coordenado por Cappelletti e Garth, que empreenderam um survey comparativo em diversos países integrantes do projeto (Cappelletti e Garth, 1988) com a preocupação de abranger os recursos e soluções disponíveis aos litigantes e seu sucesso na utilização do sistema de justiça para obtenção de reparação ${ }^{4}$.

A concepção de acesso à justiça trabalhada pelos autores é a de reivindicação de direitos e resolução de litígios sob os auspícios do Estado, de forma igualmente acessível a todos, e que produza resultados individual e socialmente justos (Cappelletti e Garth, 1988 , p. 9), incluindo também o direito de garantia de efetividade dos direitos individuais e coletivos.

A orientação predominante nas pesquisas desenvolvidas nesse período é a da abordagem conhecida como "necessidades jurídicas não atendidas" (unmet legal needs), que visava quantificar objetivamente tais necessidades ${ }^{5}$. A metodologia seguida nesses estudos era baseada na pesquisa de survey, em que se apresentava aos entrevistados uma lista de problemas que poderiam ser judicializados (seja porque a lei previa regras para solucioná-los ou porque eram frequentemente levados a advogados), indagando aos

\footnotetext{
${ }^{4}$ Na leitura de Sandefur (2008), Cappelletti e Garth cunharam o slogan "acesso à justiça" em um momento histórico de grande otimismo sobre a capacidade da lei para reduzir desigualdades, não apenas no uso de meios legais para resolver conflitos, mas no âmbito social e econômico mais geral (Sandefur, 2008, p. $340)$.

${ }^{5}$ Duas das principais referências nessa abordagem são Marks (1976) e Curran (1977).
} 
entrevistados se passaram por esses problemas listados e, uma vez que tivessem passado, se buscaram aconselhamento legal para resolvê-los.

A crítica feita a esses estudos é de que não tratariam do acesso à justiça propriamente, e sim do acesso aos serviços legais de advogados. Segundo Genn (1999), a principal limitação da abordagem de necessidades jurídicas não atendidas está no enfoque de problemas tradicionais levados à advocacia privada, supondo, portanto, que o recurso a advogados é a melhor solução para tais problemas. Na visão da autora, esses estudos deveriam ser lidos como uma busca por mensurar não o acesso à justiça, mas sim a mobilização de medidas legais formais por meio de profissionais da área jurídica.

Se a década de 1970 impulsiona a busca de mensuração da acessibilidade dos sistemas jurídicos, visando estimar as necessidades legais que existem na sociedade, a década de 1980 é, na leitura de Albiston e Sandefur (2013), um marco de inovação, com o CLRP (Civil Litigation Research Project), sediado na Universidade de Wisconsin, nos Estados Unidos 6 .

Segundo as autoras, antes do CLRP as pesquisas assumiam os conflitos como objetos encontrados no mundo e enfocavam meios justos e eficientes para resolver as disputas civis que chegavam aos tribunais. Já a partir desse projeto, passou-se a privilegiar a dimensão de construtos sociais dos potenciais conflitos legais e suas trajetórias até os tribunais. No survey conduzido pelos pesquisadores do CLRP foram entrevistadas famílias, visando identificar se elas tinham enfrentado problemas potencialmente jurídicos (os problemas foram classificados de acordo com o tipo de queixa, agregados em nove categorias gerais, envolvendo discordâncias sobre contratos, discriminação, lesões a direitos do consumidor, entre outros), e àquelas que vivenciaram algum desses problemas, indagou-se a respeito do desenrolar dos eventos e de sua chegada ou não aos tribunais (Albiston e Sandefur, 2013, p. 103).

É no CLRP que Felstiner, Abel e Sarat (1980) desenvolvem a abordagem do processamento de disputas (dispute processing research ${ }^{7}$ ), concentrando-se em um subconjunto de problemas que as pessoas percebem como pessoalmente prejudiciais e os atribuem a um terceiro culpado. Nessa abordagem, a concepção de acesso à justiça é a de um processo de "nomeação, responsabilização (culpabilização) e reivindicação", que consiste em reconhecer uma situação vivenciada como prejudicial (uma lesão), identificar um outro responsável pelo prejuízo e confrontar esse outro em busca de reparação ou remédio, com a possibilidade de busca e acesso a uma solução por meio da justiça formal ou de outro terceiro idôneo.

Felstiner, Abel e Sarat (1980) destacam que a escolha do caminho de ação (ou inação) ante o prejuízo envolve a participação de família, amigos, colegas de trabalho e organizações, que influenciam a forma como as pessoas interpretam suas experiências e avaliam suas opções de resposta.

\footnotetext{
${ }^{6}$ Para detalhes sobre o projeto, ver Grossman e Trubek (1980-1981, p. 395-399).

${ }^{7}$ Ver Sandefur (2008, p. 342).
} 
MEDINDO O ACESSO À JUSTIÇA CÍVEL NO BRASIL

Na década de 1990 a busca por mensurar acesso à justiça avança no sentido da abordagem de problemas não tradicionais, a partir da "metodologia de eventos judicializáveis", na esteira da concepção do CLRP de que as necessidades jurídicas são em grande parte dependentes do contexto social e local, sendo que fatores culturais, sociais, políticos e econômicos afetam as necessidades, atitudes e ações das pessoas nessa esfera. Essa metodologia se baseia na documentação da incidência de conflitos potencialmente legais e explora as respostas que as pessoas dão ante a vivência desses problemas e também as avaliações subjetivas que elas fazem das experiências com as instituições de justiça quando utilizadas (por exemplo, a satisfação com o processo e os resultados obtidos).

Nessa linha estão as pesquisas de Genn (1999) e Genn e Paterson (2001), que conduziram surveys na Inglaterra e na Escócia, respectivamente, para determinar: i) a incidência de problemas passíveis de solução via Justiça Cível; ii) a resposta do público ante a vivência desses problemas (se tomaram ou não alguma medida; e, tendo tomado, qual foi a medida adotada, verificando se buscaram ou não as instituições formais de justiça e por quê); iii) o padrão de resposta ante os tipos de conflitos vivenciados; iv) o tipo de auxílio prestado pela instituição buscada (informação, assistência etc.); e v) os resultados alcançados. Com base nesses cinco tópicos, seria possível estabelecer a trajetória dos conflitos.

Sandefur (2008) afirma que essas são as três linhas predominantes na busca por mensurar o comportamento declarado das pessoas em relação ao acesso à justiça (1. necessidades legais; 2 . processamento de disputas; e 3 . eventos judicializáveis ${ }^{8}$ ), sendo que elas têm em comum a adoção da metodologia de survey via apresentação aos entrevistados de longas listas de eventos específicos, que variam de estudo para estudo, mas que abrangem as categorias básicas de problemas legais, incluindo questões de consumo, habitação, emprego, família, vizinhança, burocracias públicas e lesões físicas e econômicas (calúnia, difamação, acidentes).

Além do tipo de enfoque e da lista de problemas (tipos e quantidade), essas pesquisas também variam com relação aos métodos de amostragem (população como um todo x grupos de renda baixa etc.), modos de administração (entrevista pessoal, autopreenchimento, entrevista telefônica etc.), unidades de análise (domicílio $x$ indivíduo), períodos de referência (últimos 12 meses, últimos 5 anos etc.), tipo de filtragem (filtro de trivialidade - difícil resolução x lista de problemas potencialmente judicializáveis) e formulação da questão.

Um exemplo inicial dessas pesquisas que seguem o ponto de vista de que a mensuração do acesso à justiça passa pela identificação das necessidades legais, do processamento das disputas e do reconhecimento de eventos judicializáveis é a de Genn e Paterson (2001). No questionário utilizado pelos autores, após perguntas de identificação dos respondentes para enquadramento no critério amostral, inicia-se a

\footnotetext{
${ }^{8}$ Tradução da expressão inglesa "justiciable events".
} 
estratégia de identificação de vivência de conflitos (filtragem), especificando o interesse apenas nos conflitos particulares, ou seja, aqueles que os entrevistados vivenciaram enquanto pessoas físicas, e que entenderam ser de difícil solução:

Eu gostaria de perguntar sobre diferentes tipos de problemas que você (ou seu cônjuge) possam ter tido. Por favor, considere apenas os problemas em que vocês estiveram pessoalmente envolvidos, e não situações em que vocês ajudaram alguém com problemas. Estamos interessados nos problemas que vocês experimentaram como pessoas físicas, não aqueles experimentados por vocês enquanto empregadores ou qualquer negócio que vocês possam executar. Nós também estamos interessados apenas em problemas que vocês tiveram desde a idade de 18 anos. Desde [DATA], vocês tiveram quaisquer problemas ou conflitos que eram difíceis de resolver relacionados à... (Genn e Paterson, 2001, p. 292) ${ }^{9}$.

Nessa triagem, a entrevista segue indagando acerca de uma série de situações e áreas de controvérsias por blocos temáticos, focando sempre em problemas de difícil resolução, pertinentes a questões financeiras, de consumo (produtos e serviços defeituosos), aluguel e imóveis, emprego, família, ferimentos ou problemas de saúde, discriminação em razão de sexo, raça ou deficiência, entre outros. E, para cada situação que o entrevistado afirma ter vivenciado (pessoalmente ou o cônjuge), são feitas perguntas acerca da estratégia de resolução adotada (considerando o problema vivenciado mais recentemente):

Pensando no [PROBLEMA mais recente/segundo mais recente/terceiro mais recente], você (ou seu marido/esposa/parceiro/parceira) adotou alguma das seguintes medidas nesse cartão para tentar resolver o problema [CARTÃO]:

1) Falou ou escreveu para o outro lado envolvido sobre como resolver o problema; 2) Procurou aconselhamento sobre como tentar resolver o problema; 3) Ameaçou o outro lado envolvido com uma ação judicial; 4) Foi ao tribunal/iniciou processo judicial ou uma arbitragem; 5) Buscou mediação ou conciliação; 6) Levou o problema a um ombudsman; 7) Tomou algum outro tipo de medida para tentar resolver o problema; 8) Não fez nada (Genn e Paterson, 2001, p. 293) ${ }^{10}$.

\footnotetext{
${ }^{9}$ No original, "I would like to ask you about different sorts of problems you (husband, wife, partner) might have had. Please only include problems that you have had yourself, not situations where you helped somebody else with their problems. We are interested in those problems you have experienced as an individual, not those experienced by you as employer or any business you might run. We are also only interested in problems you have had since the age of 18."Since [DATE], have you had any problems or disputes that were difficult to solve to do with...".

${ }^{10}$ No original "thinking of the (most recent/ 2 nd most recent/ 3rd most recent) PROBLEM, did you (or your husband/wife/partner) do any of the hints on this card to try to resolve it? [CARD]: 1. Talked or wrote to the other side about solving the problem; 2 . sought advice about trying to solve the problem; 3 . threatened other side with legal action; 4 went to court, tribunal or arbitration/started a court case or arbitration; 5. went to mediation of conciliation; 6. took the problem to an ombudsman; 7. took some other kind of action to try to solve the problem; 8 . did nothing.
} 
MEDINDO O ACESSO À JUSTIÇA CÍVEL NO BRASIL

O survey na Escócia apontou que $26 \%$ dos entrevistados vivenciaram pelo menos um problema de difícil solução - o survey da Inglaterra, conduzido alguns anos antes, também por Genn, apresentou gama maior de pessoas que relataram problemas, $40 \%$. $\mathrm{Na}$ Inglaterra, entre os que vivenciaram problemas, a principal estratégia adotada foi tentar resolver o problema diretamente (68\%), sem o intermédio de aconselhamento ou ajuda legal, sendo que apenas $20 \%$ escolheram o caminho das cortes.

Para além do objetivo descritivo de levantar a incidência de experiências com eventos de Justiça Cível e dos caminhos de gestão de conflitos adotados, essas pesquisas buscam explicar a escolha pelo uso do sistema estatal de justiça, focando nas barreiras de acesso e discutindo formas de superá-las. Elementos de estrutura social são priorizados nessas pesquisas, identificando como variáveis explicativas para as barreiras de acesso à justiça estatal as características socioeconômicas, notadamente, renda e escolaridade. Mas fatores de informação e motivação também são levados em conta, considerando a consciência e o reconhecimento de que determinado problema caracteriza-se como um conflito potencialmente jurídico, passível de resolução via justiça formal, e a vontade e a disponibilidade para iniciar uma ação judicial para solucionar esse problema, além do conhecimento das instituições formais de justiça, sua localização e a confiança que se tem nelas.

O conjunto de pesquisas tem mostrado que o tipo de conflito vivenciado, assim como o local de moradia, também ajuda a explicar a utilização das instituições formais de justiça.

É exatamente por isso que essas pesquisas representaram uma superação dos estudos realizados sob a ótica do Florence Project, que via nas questões processuais, na relação com advogados e com as instituições do sistema de justiça variáveis explicativas do acesso à justiça, já comentados anteriormente.

Em texto recente sobre o estado da arte da mensuração do acesso à justiça, Albiston e Sandefur (2013) destacam que o aprendizado acumulado em quatro décadas na tentativa de mensurar acesso à justiça nos ensina que a maioria das pessoas que experimentam algum problema de justiça não recorre a advogados ou ao sistema formal de justiça em busca de reparação, e isso independentemente do seu nível de renda. Nesse sentido, o desafio que entendem estar posto a esse campo de estudos é o de trabalhar com uma compreensão mais ampla, tanto do que significa acesso à justiça quanto do que a falta de acesso implica.

$\mathrm{Na}$ leitura de Albiston e Sandefur (2013), é preciso deixar de pensar políticas públicas de acesso à justiça como políticas de combate à pobreza unicamente, e voltar o olhar para a sociedade como um todo, visando entender como as pessoas pensam e agem sobre suas experiências potencialmente judicializáveis, enquadrando o acesso à justiça como uma questão universal, em vez de uma preocupação limitada a grupos estigmatizados ("excluídos" ou "hipossuficientes"). Esses autores defendem que a investigação dos determinantes das barreiras de acesso deve considerar não apenas variáveis socioeconômicas, mas também os significados sociais construídos em torno da 
reivindicação de direitos, como a identidade estigmatizada dos requerentes ou a dificuldade de compreender um conflito como um problema legal, passível de solução jurídica (Albiston e Sandefur, 2013, p. 119-120).

Na sequência, exploramos como o campo de pesquisa de mensuração do acesso à justiça tem se desenvolvido no Brasil.

\section{Mensurando o acesso à justiça no Brasil}

Em artigo de meados da década de 1990, Junqueira (1996) documentou o surgimento e o desenvolvimento do campo de estudos sobre acesso à justiça no Brasil, destacando que a temática ingressa no cenário acadêmico e político brasileiro apenas na década de 1980, sendo notória a ausência do Brasil no Florence Project.

O surgimento desse campo no Brasil é fortemente influenciado pelo estudo de Boaventura de Sousa Santos na favela do Jacarezinho, no Rio de Janeiro, e pela discussão sobre pluralismo jurídico. Santos (1977) documentou as dificuldades de acesso à justiça enfrentadas por moradores da favela carioca do Jacarezinho, destacando como essas dificuldades levavam à existência de uma pluralidade normativa, com as regras de um direito local (informal) convivendo com o direito estatal (formal) na maneira como os moradores resolviam seus conflitos.

Junqueira (1996) afirma que o campo de estudos de acesso à justiça nasce no país com a preocupação de

se expandirem para o conjunto da população direitos básicos aos quais a maioria não tinha acesso tanto em função da tradição liberal-individualista do ordenamento jurídico brasileiro, como em razão da histórica marginalização socioeconômica dos setores subalternizados e da exclusão político-jurídica provocada pelo regime pós-64 (Junqueira, 1996, p. 1).

Chama, ainda, atenção para a forte influência das invasões urbanas na configuração do campo, sobretudo a partir da Escola do Recife (Joaquim Falcão, Solange Couto, Luciano Oliveira).

Junqueira classifica as pesquisas sobre acesso à justiça no Brasil em dois eixos: o que enfoca o acesso coletivo à justiça, no início da década de 1980, e o que investiga formas estatais, não estatais e mecanismos informais de resolução de conflitos individuais, sobretudo a partir da instalação dos Juizados Especiais de Pequenas Causas em meados da década de 1980.

Dando continuidade a esses estudos, durante os anos de 1980, foram desenvolvidas pesquisas em torno, principalmente, de dois pontos de vista diferentes. De um lado, os trabalhos organizados sob a ótica do direito processual por acadêmicos ligados às faculdades de direito e, mais especificamente, aos departamentos de processo civil desses cursos, que analisavam os impactos das reformas processuais e institucionais no que diz respeito ao acesso à justiça, como acesso ao Judiciário. Assim, a 
MEDINDO O ACESSO À JUSTIÇA CÍVEL NO BRASIL

institucionalização dos Juizados Especiais Cíveis e Criminais e da Defensoria Pública, além do fortalecimento do Ministério Público, com a Constituição Federal de 1988, a Lei da Ação Civil Pública (Lei 7.347/1985) e o Código de Defesa do Consumidor (Lei 8.078/1990) foram alguns dos objetos de estudo privilegiados nessa perspectiva.

De outro lado, os trabalhos feitos sob a ótica da sociologia jurídica, com forte influência do movimento Law and Society que teve como um de seus espaços de formação a Escola de Direito da Universidade de Wisconsin, Madison, nos Estados Unidos, por onde passaram vários acadêmicos brasileiros, como José Eduardo Faria e Eliane Junqueira. Sob a influência de Boaventura de Sousa Santos, que passou pela mesma universidade, e sob a ótica do pluralismo jurídico, que aponta o convívio de formas alternativas (informais) ao direito estatal (formais) na solução de conflitos, nesses estudos o acesso à justiça estava relacionado à assistência jurídica, à administração da justiça, aos direitos sociais e ao reconhecimento de direitos. Diferentemente das pesquisas no âmbito do direito processual civil comandadas por Ada Pelegrini Grinover, Cândido Dinamarco e Kazuo Watanabe (1988), essas pesquisas com viés empírico contribuíram para a identificação dos obstáculos na solução dos conflitos (Faria, 1989).

Importante pontuar que no início da década de 1980 foi fundado o Idesp (Instituto de Estudos Econômicos Sociais e Políticos de São Paulo), que a partir dos anos de 1990 voltou seu olhar para o Poder Judiciário e as instituições de justiça brasileiras, com uma série de pesquisas empíricas coordenadas por Sadek (1994, 1995, 2009, 2014), que se tornou uma das principais referências em estudos sobre acesso à justiça no país, entendendo esse acesso enquanto a "busca de solução pacífica de conflitos e do reconhecimento de direitos" (Sadek, 2014, p. 57). Os estudos de Sadek apontam que a realização do direito de acesso à justiça está sujeita a condicionantes de natureza econômica, social, cultural e política.

A vasta maioria dos estudos nacionais dedicou-se à análise de indicadores objetivos e subjetivos de percepção para discutir acesso à justiça, sendo que foi somente no final dos anos 1980 que ocorreu o primeiro grande esforço nacional de mensuração de acesso à justiça a partir de indicadores subjetivos de comportamento, via Instituto Brasileiro de Geografia e Estatística (IBGE), como parte integrante do suplemento "Participação Político-Social", publicado no volume 1 - "Justiça e Vitimização", da Pesquisa Nacional por Amostra de Domicílios (PNAD).

Essa iniciativa foi publicada em 1988 e voltou a ser conduzida apenas na PNAD de 2009. A concepção de acesso à justiça com a qual o levantamento trabalha é bastante ampla. Lê-se nas notas metodológicas e no manual de entrevista da PNAD (2009) que acesso à justiça implica "a formulação de políticas públicas destinadas a garantir os direitos fundamentais e a prevenir conflitos".

Apesar da amplitude da concepção, apenas cinco perguntas foram dedicadas à temática. O módulo de justiça inicia com a pergunta sobre a vivência de "conflito grave" nos últimos cinco anos anteriores à data de realização da entrevista, havendo uma lista codificada de oito áreas, com a opção de outra área que não as já especificadas. Há uma 
alteração na metodologia adotada na pesquisa entre as tomadas de 1988 e 2009. Enquanto na primeira (1988) perguntava-se acerca do conflito mais recente vivenciado pelo entrevistado, em 2009 perguntou-se sobre o conflito considerado pelo entrevistado como o mais grave.

Indique a área da situação de conflito mais grave que teve no período de 27 de setembro de 2004 a 26 de setembro de 2009? R: 1) Trabalhista; 2. Criminal; 3. Família; 4. Terras/moradia; 5 . Serviços de água, luz e telefone; 6. Impostos/tributação; 7. Benefícios do INSS/previdência; 8. Bancos/instituições financeiras; 9. Outra (especifique); 10. Não teve problema (PNAD, 2009, p. 71).

Toda forma de mensuração acarreta limitações e perda de informação, mas acreditamos que o filtro de trivialidade utilizado na PNAD seja muito forte, e se o objetivo é mensurar acesso e uso das instituições formais de justiça, tal filtro pode levar à subnotificação, especialmente se considerarmos casos de consumo, que podem não ser tomados como "graves" por muitos, e o fato de que a situação mais grave vivenciada por uma pessoa pode não ser aquela na qual se busca o caminho das instituições formais (especialmente se considerarmos casos de família e de violência doméstica, por exemplo).

A inclusão do filtro de trivialidade pode ser um dos fatores que ajudam a entender a diminuição na proporção dos que declararam ter vivenciado algum conflito entre as duas tomadas da pesquisa: no levantamento de $1988,10,5 \%$ da população de 18 anos ou mais de idade declarou ter passado por alguma situação de conflito no período de referência de cinco anos, considerando o último conflito vivenciado. Já no levantamento de 2009, 9,4\% da população de 18 anos ou mais de idade declarou ter vivenciado algum conflito grave nos últimos cinco anos.

Nosso argumento aqui não é descartar o uso de filtros de trivialidade, mas sim questionar seu desenho e o tipo de viés que ele produz. O filtro adotado por Genn (1999) e Genn e Paterson (2001), por exemplo, é mais leve, considerando problemas "difíceis de resolver". No entanto, assim como o filtro da PNAD, o de Genn implica que a medida deixa de ser acesso e uso das instituições formais de justiça e passa a ser adoção de caminhos de gestão de conflitos ante situações graves ou de difícil solução. Portanto, há aqui um potencial viés de validade de face da medida.

As áreas de conflito mais mencionadas na PNAD 2009 foram trabalhista (23,3\%), família $(22,0 \%)$ e criminal $(12,6 \%)$. Na sequência, problemas de consumo com serviços de água, luz e telefone $(9,7 \%)$; INSS e previdência $(8,6 \%)$; consumo de serviços bancários e de instituições financeiras $(7,4 \%)$; terras e moradia $(4,8 \%)$ e impostos ou tributação $(1,2 \%)$.

Para cada conflito que os entrevistados declararam ter vivenciado, pergunta-se, no questionário da PNAD, sobre o tipo de ajuda buscada para solucioná-lo, havendo uma lista codificada com sete opções, e a possibilidade de registrar outras respostas que não 
MEDINDO O ACESSO À JUSTIÇA CÍVEL NO BRASIL

as previamente listadas.

Onde tentou buscar a solução do seu conflito? 1. Justiça (foi movida uma ação judicial formal); 2. Juizado Especial (antigo Juizado de Pequenas Causas); 3. Amigo/parente; 4. Polícia; 5. Igreja; 6. Procon (Programa de Orientação e Proteção do Consumidor); 7. Sindicato/associação; 8. Outro (especifique); 9. Não buscou solução (PNAD, 2009, p. 71).

A maneira de levantar informações acerca da gestão do conflito também pode gerar algum viés, em virtude de assumir que buscar solução para o problema é a atitude esperada, pois na forma de perguntar não se coloca de antemão a possibilidade de o entrevistado simplesmente não ter buscado solução. Evidente que em uma pesquisa com a extensão amostral da PNAD esses potenciais vieses da forma de perguntar podem ser minimizados - o que se torna um problema maior no caso de pesquisas amostrais de menor fôlego, com amostras inferiores a 100 mil casos.

Em 2009, os dados da PNAD revelaram que 92,7\% dos entrevistados que declararam ter vivenciado conflito buscaram algum tipo de solução, sendo os caminhos mais frequentes a justiça $(57,8 \%)$ e os juizados especiais $(12,4 \%)$, vindo na sequência a procura pela polícia $(6,6 \%)$ e pelo Procon $(3,9 \%)$.

Àqueles que declararam ter utilizado outro caminho que não o da justiça ou dos juizados, perguntou-se o motivo de não ter buscado ajuda judicial, havendo nove opções pré-codificadas de resposta, e a possibilidade de registrar outras respostas que não as listadas.

Qual foi o principal motivo de a justiça não ter sido procurada? 1. Custaria muito caro; 2. Era muito longe; 3. Por falta de provas; 4. Demoraria muito; 5. Cabia à(s) outra(s) parte(s) iniciar(em) a ação; 6. Por medo da(s) outra(s) parte(s) envolvida(s); 7. Resolveu o problema por meio de mediação ou conciliação - Ou seja, resolveu o problema por meios alternativos de resolução de conflitos ou mecanismos de autocomposição; 8. Não acredita na justiça; 9. Não sabia que podia utilizar a justiça; 10 . Outros (Especifique) - Quando o motivo não se enquadrar entre os anteriores (PNAD, 2009, p. 71).

Os principais motivos relatados foram: terem solucionado o problema por meio de mediação ou conciliação $(27,6 \%)$; a percepção de que a busca das instituições judiciais é morosa $(15,9 \%)$; e o fato de não saberem que poderiam ter usado a justiça para o tipo de problema vivenciado $(6,8 \%)$.

Por fim, pergunta-se acerca do tempo de duração do conflito até sua solução, e, no caso de ter havido solução, a quem os entrevistados atribuem a responsabilidade (mérito): 
Quanto tempo se passou entre o início e a solução do conflito? 1. Até 1 ano; 2. Mais de 1 a 2 anos; 3. Mais de 2 a 3 anos; 4 . Mais de 3 a 4 anos; 5 . Mais de 4 a 5 anos; 6. Não lembra; 7. Ainda não houve solução (PNAD, 2009, p. 72).

Se houve solução, qual foi o principal responsável? 1. Justiça; 2. Juizado Especial; 3. Amigo/Parente; 4. Polícia; 5. Igreja; 6. Procon; 7. Advogado Particular/Defensoria Pública; 8. Sindicato/ Associação; 9. Ministério Público; 10. Outros (Especifique) - Quando o principal responsável pela solução do problema não for nenhum dos assinalados anteriormente (PNAD, 2009, p. 72).

Quase metade das pessoas tiveram seus conflitos solucionados $(49,2 \%)$, sendo a maioria no intervalo de tempo de um ano.

O Procon ficou com a posição de principal responsável por conflitos solucionados no período, com $69,4 \%$ das menções. E a justiça foi a que menos solucionou conflitos $56,5 \%$ das pessoas que buscaram esse caminho não haviam encontrado solução para o problema até o momento da entrevista.

Os dados da PNAD permitem também observar que, quanto maior o nível de escolaridade e as faixas de rendimento mensal domiciliar per capita, maiores são os percentuais de pessoas que vivenciaram situação de conflito no período, assim como é maior a proporção dos que buscaram o caminho da justiça, reforçando as características socioeconômicas como importantes preditores de acesso à justiça.

Outra iniciativa de criar indicadores subjetivos de acesso à justiça vem do Ipea, via projeto Sistema de Indicadores de Percepção Social (Sips), de 2011. Essa pesquisa indagou acerca do problema "mais sério" que o entrevistado alguma vez enfrentou, a partir de uma lista estimulada de 13 situações.

Vou mencionar alguns tipos de problemas que as pessoas costumam enfrentar e gostaria que você me dissesse, dentre esses, qual foi o mais sério que já enfrentou: R: 1 . família; 2 . vizinhança; 3. relações de trabalho; 4. pessoas com as quais fez negócio; 5. empresas com as quais fez negócio; 6. crime e violência; 7. cobrança de impostos ou outros conflitos com o fisco; 8. previdência, assistência social ou demandas por direitos sociais; 9. trânsito; 10 . imóvel ou terra; 11 . criança e adolescente; 12 . violência de agentes do Estado; 13. problemas com repartições ou empresas públicas (Sips Justiça - Ipea, 2011, p. 9).

Embora o filtro de trivialidade do Ipea seja mais ameno que o utilizado na PNAD, ainda assim pode levar ao viés de subnotificação de outras situações consideradas "menos sérias" e a não abranger necessariamente acesso e uso das instituições formais de justiça, pelos mesmos motivos já mencionados no caso da formulação da pergunta do questionário da PNAD. 
MEDINDO O ACESSO À JUSTIÇA CÍVEL NO BRASIL

As situações mais recorrentes entre os entrevistados na pesquisa do Ipea foram família $(24,86 \%)$, relações de trabalho $(15,43 \%)$, vizinhança $(11,71 \%)$ e crime e violência $(10,74 \%)$.

A abordagem da gestão de conflitos também tende a favorecer a ação dos indivíduos em detrimento da inação, dada a forma de perguntar ("Quem você procurou em primeiro lugar para resolver esse problema?").

Note que não estamos aqui questionando a qualidade dessas pesquisas, mas, sim, pontuando qual é exatamente o fenômeno que elas estão mensurando (validade do construto).

Na próxima seção apresentamos a abordagem com a qual vimos trabalhando desde 2010, em pesquisa conduzida pela FGV Direito São Paulo, como parte integrante do projeto ICJ Brasil ${ }^{11}$. A principal diferença na medida proposta é a inversão de prioridade, que deixa de ser a situação vivenciada e passa a ser a busca efetiva das instituições de justiça - o que explicaremos de forma mais detida na sequência.

\section{Proposta de uma medida de acesso à Justiça Cível}

A concepção de acesso à justiça trabalhada pelo ICJ Brasil considera tanto o sentido processual, ou seja, as instâncias e os procedimentos legais formais para resolução de litígios, quanto o sentido substantivo, que implica o acesso a uma resolução justa de conflitos, por meios idôneos (que não necessariamente a justiça formal), levando em conta também o conhecimento e a percepção subjetiva dos atores acerca de direitos e vias institucionais de sua garantia.

Para mensurar acesso à justiça em sentido processual, o IC] Brasil aborda diretamente a experiência com a justiça. A pergunta direcionada aos entrevistados é no sentido de averiguar se já buscaram o Judiciário ou já entraram com processo na justiça, e não mais, como nas pesquisas comentadas anteriormente, sobre a situação mais grave ou séria de conflito vivenciada. Dessa forma, invertemos a prioridade do interesse da situação para a experiência com a instituição [O (a) Sr.(a) ou alguém do seu domicilio já utilizou o Judiciário, ou seja, já entrou com algum processo ou ação na justiça?]. Essa forma de perguntar foi utilizada para mensurar a adjudicação e concretização de conflitos vivenciados em disputas judiciais.

Ao longo dos anos, observamos que entre $45 \%$ e $50 \%$ dos entrevistados

\footnotetext{
${ }^{11} \mathrm{O}$ Índice de Confiança na Justiça Brasileira, projeto coordenado por Luciana Gross Cunha na FGV Direito São Paulo, foi concebido para medir a opinião pública sobre o desempenho judicial no Brasil desde 2009. A população-alvo da pesquisa são brasileiros e brasileiras a partir de 18 anos de idade, residentes em áreas urbanas. A amostra é distribuída pelos sete estados (São Paulo, Rio de Janeiro, Minas Gerais, Pernambuco, Bahia, Rio Grande do Sul e Amazonas) e o Distrito Federal, que, juntos, representam cerca de $55 \%$ da população do país, de acordo com dados do Censo do IBGE 2010. A base de amostragem foi construída a partir de um intervalo de $95 \%$ de confiança e erro absoluto de 2,5\%, fixando o tamanho da amostra em 1.670 respondentes a cada trimestre. As entrevistas são realizadas por telefone, celular e fixo, a partir de um questionário de 25 minutos de duração. Os relatórios podem ser acessados pelo link: <http://direitogv.fgv.br/en/publicacoes/icj-brasil>.
} 
declararam já ter buscado a justiça alguma vez (pessoalmente ou alguém residente no domicílio, uma vez que nossa unidade amostral é o domicílio).

\section{Gráfico 1 \\ Entrevistados que declararam ter utilizado o Judiciário ou ingressado com ação na justiça (\%)}

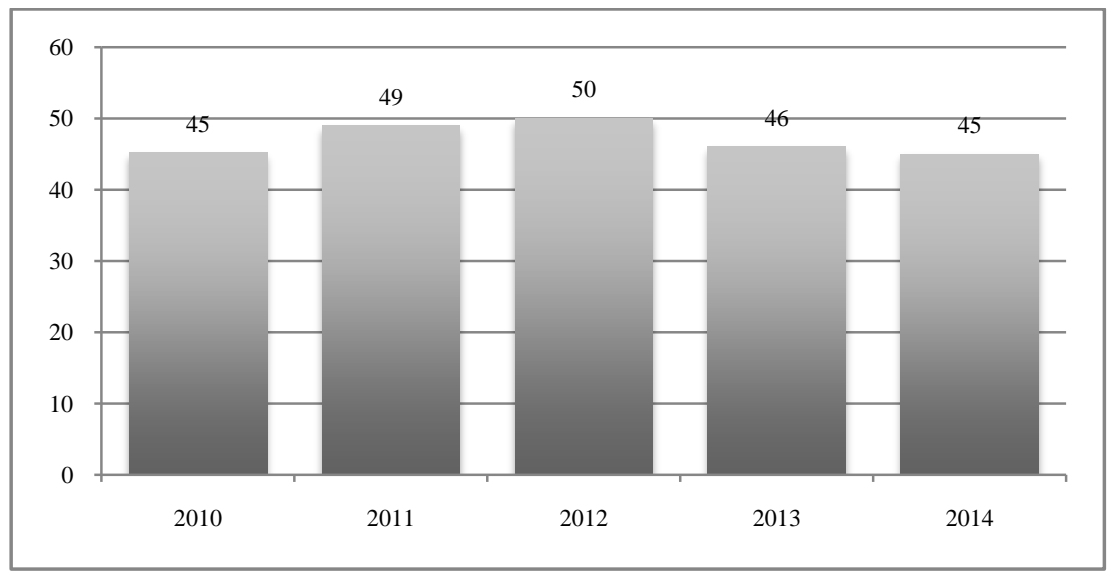

Fonte: Elaboração própria com base em dados do survey Índice de Confiança na Justiça no Brasil, FGV (2010-2014).

Base: 2010: 4.685 entrevistas; 2011: 6.213 entrevistas; 2012: 6.509 entrevistas; 2013: 6.629 entrevistas; 2014: 6.623 entrevistas.

Esses dados podem parecer à primeira vista superestimados, sobretudo quando comparados aos resultados de pesquisas anteriores, mas devemos considerar três aspectos. O primeiro é o critério amostral. Estamos aqui fazendo inferências para a população brasileira residente em áreas urbanas dos estados de Minas Gerais, Pernambuco, Rio Grande do Sul, Bahia, Rio de Janeiro, São Paulo, e do Distrito Federal, e a partir de 2012 também do estado do Amazonas. No total, esses estados e o DF correspondem a aproximadamente $55 \%$ da população brasileira de 18 anos ou mais de idade. Além disso, consideramos apenas as pessoas que têm telefone (em média, $80 \%$ da amostra é realizada via números de telefone fixo e $20 \%$ via números de telefone celular).

O segundo aspecto é a compreensão que as pessoas têm do que está sendo perguntado, mais especificamente o que entendem por utilizar o Judiciário ou ingressar com processo ou ação na justiça - ponto que discutiremos em detalhe mais adiante. E o terceiro, o enquadramento da questão, enfocando diretamente a busca pela instituição e não a vivência de situações graves ou de difícil resolução - daí observarmos proporção maior de acesso se comparado aos estudos anteriores.

Interessa-nos saber, também, quantas vezes os usuários declarados do Judiciário optaram, em situações de conflito, pelo caminho das instituições formais para a resolução dessas situações. Assim, perguntamos sobre a quantidade de vezes que já utilizaram o Judiciário [Quantas vezes o(a) Sr.(a) ou alguém do seu domicilio já utilizaram o 
MEDINDO O ACESSO À JUSTIÇA CÍVEL NO BRASIL

Judiciário, ou seja, com quantos processos ou ações já entraram na justiça?]. O resultado é que a maior parte dos entrevistados ingressou apenas uma vez (média $=1$ ), mas pouco mais de $40 \%$ dos entrevistados são usuários recorrentes (utilizaram duas ou mais vezes) o caminho da justiça estatal.

\section{Gráfico 2}

\section{Entrevistados de acordo com a quantidade declarada de ações (\%)}

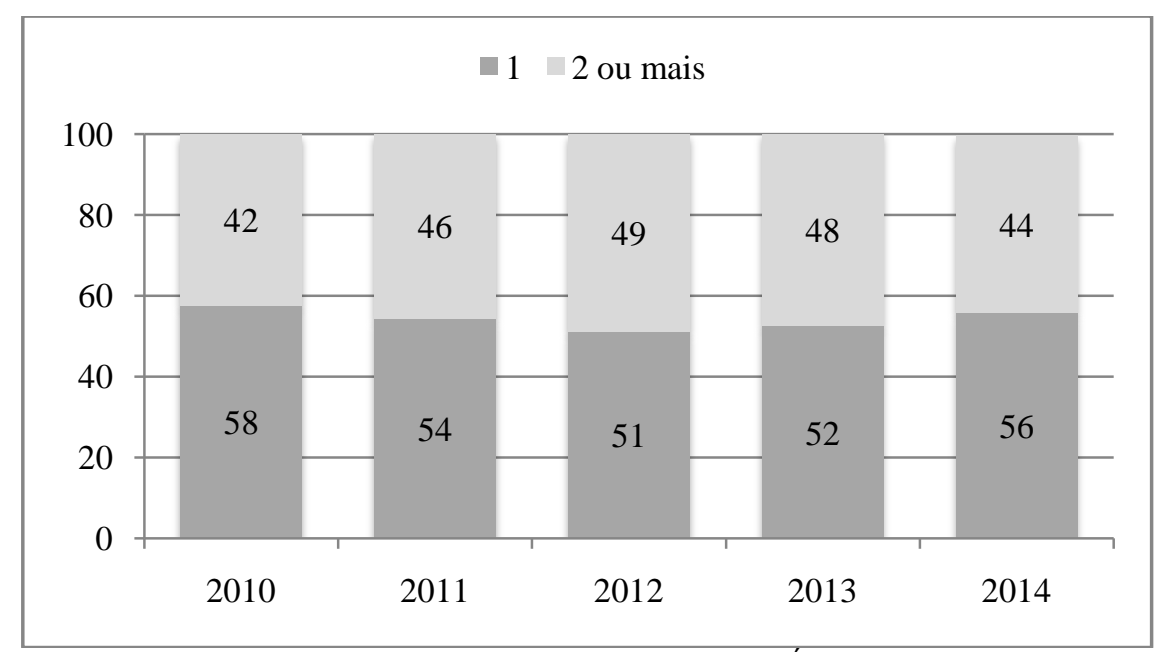

Fonte: Elaboração própria com base em dados do survey Índice de Confiança na Justiça no Brasil, FGV (2010-2014).

Base: 2010: 2.117 entrevistas; 2011: 3.044 entrevistas; 2012: 3329 entrevistas;

2013: 3.057 entrevistas; 2014: 2.027 entrevistas.

Além da frequência de uso, perguntamos acerca do tempo, ou seja, quando se deu essa experiência com a justiça. Para aqueles que ingressaram apenas com uma ação, indagamos sobre o ano em que entrou com o processo e, para os usuários recorrentes, quando foi o último ingresso [Em que ano entrou com esse processo ou ação? e Em que ano entrou com o processo ou ação mais recente?]. Observamos que a maioria dos processos é recente, estando na década de 2000, até três anos antes da data da entrevista, com pouco menos de um terço datando do período de dois anos antecedentes à data da entrevista. 
Tabela 1

Ação ou processo na justiça por data de ingresso (\%)

\begin{tabular}{|l|c|c|c|c|c|}
\hline & $\mathbf{2 0 1 0}$ & $\mathbf{2 0 1 1}$ & $\mathbf{2 0 1 2}$ & $\mathbf{2 0 1 3}$ & $\mathbf{2 0 1 4}$ \\
\hline Até 1999 & 14 & 13 & 9 & 9 & 8 \\
\hline $\begin{array}{l}\text { De 2000 até 3 anos antes (ano referência da } \\
\text { pesquisa) }\end{array}$ & 54 & 54 & 60 & 62 & 64 \\
\hline Últimos 2 anos (desde referência da pesquisa) & 29 & 26 & 28 & 28 & 27 \\
\hline Não lembra & 3 & 7 & 3 & 1 & 1 \\
\hline Base (n) & $\mathbf{2 . 1 1 7}$ & $\mathbf{3 . 0 4 4}$ & $\mathbf{3 . 3 2 9}$ & $\mathbf{3 . 0 5 7}$ & $\mathbf{2 . 0 2 7}$ \\
\hline
\end{tabular}

Fonte: Elaboração própria com base em dados do survey Índice de Confiança na Justiça no Brasil, FGV (2010-2014).

Um dos itens de maior preocupação no survey que conduzimos é a compreensão dos entrevistados acerca daquilo que visamos mensurar, sendo que, ao longo das tomadas anuais, buscamos aprimorar a medida. E, diante do elevado percentual de respostas positivas que obtivemos para o uso do Judiciário no primeiro ano do survey, conduzimos entrevistas cognitivas e percebemos que alguns entrevistados tomavam a procura por qualquer instituição formal de justiça como significando "entrada na justiça" ou "abertura de processo", incluindo nesse rol desde uma simples ligação para a polícia, a realização de um boletim de ocorrência $(\mathrm{BO})$, até a busca de atendimento na Defensoria Pública. Assim, a partir do segundo ano de pesquisa, incluímos a especificação da instituição para minimizar esse viés de resposta.

Àqueles que respondem afirmativamente à questão do uso da justiça, perguntamos acerca da instituição a que recorreram [ $E$ qual Judiciário foi utilizado quando entrou com o processo? (LER OPÇÕES): 1. Justiça comum, estadual ou federal; 2. Justiça do Trabalho; 3. Juizado Especial; 4. Justiça Eleitoral; ou 5. Algum outro tipo de justiça (especificar qual)].

A maioria dos entrevistados afirmou ter utilizado a justiça comum estadual, ou os juizados, sendo que uma minoria, que girou entre $5 \%$ e $9 \%$, mencionou outras instituições, como a Polícia ou a Defensoria Pública (usualmente pessoas de menor renda e escolaridade).

Outra preocupação que passamos a ter a partir de 2014 é a especificação da experiência, se pessoal, ou seja, o respondente foi o autor da ação (o que ocorreu em $64 \%$ dos casos), ou se foi outra pessoa do domicílio ( $24 \%$ das vezes foram cônjuges, pais, filhos ou irmãos do respondente, e em $13 \%$ dos casos, outros membros do domicílio, como cunhados, tios ou avós).

Perguntamos, ainda, acerca do problema que precisava ser resolvido quando buscaram a justiça [Qual o motivo de ter precisado do Judiciário, ou seja, qual a causa ou problema que precisava ser resolvido?]. As respostas a essa pergunta foram abertas, e posteriormente codificadas. Entre respostas comuns aparecem colocações como "para receber valores de insalubridade que não foram pagos"; "a empresa não pagou despesas 
médicas de um acidente de trabalho"; "fui demitido sem justa causa"; "erro no cálculo para pagamento de aposentadoria"; "recebi conta de telefone com valor muito alto"; etc. Os três temas mais recorrentes ao longo de todos os anos da pesquisa estiveram ligados às esferas de trabalho, consumo e família, em sintonia com as pesquisas anteriormente mencionadas.

Tabela 2

Tipo de Judiciário utilizado (\%)

\begin{tabular}{|l|c|c|c|c|}
\hline & $\mathbf{2 0 1 1}$ & $\mathbf{2 0 1 2}$ & $\mathbf{2 0 1 3}$ & $\mathbf{2 0 1 4}$ \\
\hline Justiça comum/juizados & 58 & 68 & 65 & 64 \\
\hline Justiça do Trabalho & 32 & 28 & 29 & 30 \\
\hline Outro (Polícia, Defensoria) & 9 & 5 & 5 & 5 \\
\hline Base (n) & $\mathbf{3 . 0 4 4}$ & $\mathbf{3 . 3 2 9}$ & $\mathbf{3 . 0 5 7}$ & $\mathbf{2 . 0 2 7}$ \\
\hline
\end{tabular}

Fonte: Elaboração própria com base em dados do survey Índice de Confiança na Justiça no Brasil, FGV (2010-2014).

Tabela 3

Área do problema que foi levado à justiça (\%)

\begin{tabular}{|l|c|c|c|c|c|}
\hline & $\mathbf{2 0 1 0}$ & $\mathbf{2 0 1 1}$ & $\mathbf{2 0 1 2}$ & $\mathbf{2 0 1 3}$ & $\mathbf{2 0 1 4}$ \\
\hline Trabalho & 37 & 40 & 39 & 34 & 35 \\
\hline Consumo & 21 & 23 & 24 & 23 & 26 \\
\hline Família & 21 & 17 & 16 & 23 & 16 \\
\hline Criminal & 5 & 5 & 5 & 5 & 4 \\
\hline Trânsito & 5 & 5 & 5 & 4 & 4 \\
\hline Não lembra & 3 & 3 & 3 & 2 & 3 \\
\hline $\begin{array}{l}\text { Outro (erro médico, poder público, } \\
\text { vizinhos) }\end{array}$ & 7 & 8 & 9 & 9 & 12 \\
\hline Base (n) & $\mathbf{2 . 1 1 7}$ & $\mathbf{3 . 0 4 4}$ & $\mathbf{3 . 3 2 9}$ & $\mathbf{3 . 0 5 7}$ & $\mathbf{2 . 0 2 7}$ \\
\hline
\end{tabular}

Fonte: Elaboração própria com base em dados do survey Índice de Confiança na Justiça no Brasil, FGV (2010-2014).

A maioria dos processos iniciados já havia se encerrado, e na maior parte deles os entrevistados tiveram ganho de causa (Gráfico 3). Esses dados foram obtidos perguntando-se aos entrevistados acerca da resolução do conflito, estimulando as opções de resposta [Conseguiu resolver o problema via Judiciário? (LER OPÇÕES): 1. Sim, ganhou a ação; 2. Não, perdeu a ação; ou 3. Ainda não, pois a ação não foi julgada]. 


\section{Gráfico 3}

Entrevistados de acordo com resolução do caso (\%)

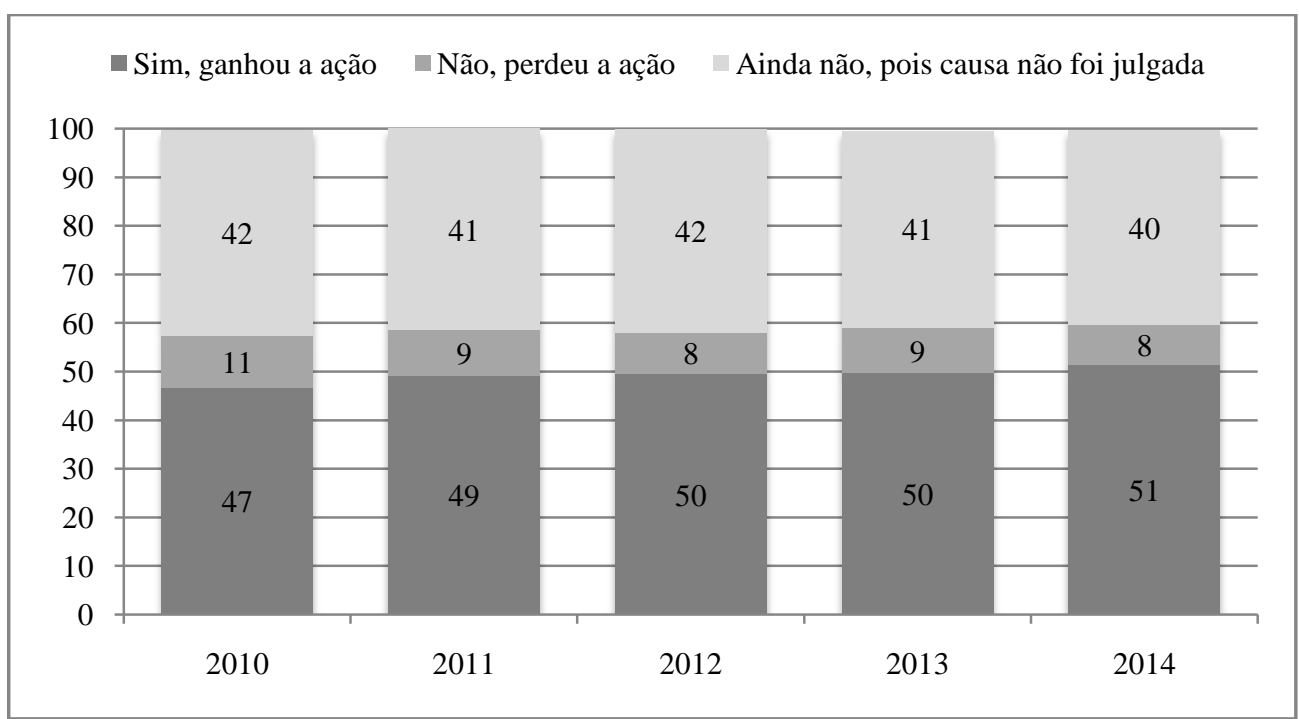

Fonte: Elaboração própria com base em dados do survey Índice de Confiança na Justiça no Brasil, FGV (2010-2014).

Base: 2010: 2.117 entrevistas; 2011: 3.044 entrevistas; 2012: 3329 entrevistas; 2013: 3.057 entrevistas; 2014: 2.027 entrevistas.

E, por fim, interessava-nos mensurar o nível de satisfação dos entrevistados com sua experiência na justiça, indagando acerca da sua satisfação com o processo [Em relação ao nível de satisfação com o Judiciário neste caso, o(a) Sr.(a) diria que está (LER OPÇÕES): 1. Muito insatisfeito; 2. Um pouco insatisfeito; 3. Um pouco satisfeito; ou 4. Muito satisfeito. No caso de ser outra pessoa que não o respondente, perguntamos: $O(a)$ Sr.(a) saberia dizer com relação ao nível de satisfação do(a) (AUTOR DA AÇÃO) se ele(ela) ficou (LER OPÇÕES): 1. Muito insatisfeito; 2. Um pouco insatisfeito; 3. Um pouco satisfeito; ou 4. Muito satisfeito, sendo aceitas também espontaneamente respostas acerca da indiferença do respondente ("nem satisfeito, nem insatisfeito") e, para o caso de outra pessoa ter sido autora do processo, a opção "não sabe"].

Notamos que ao longo dos anos houve uma divisão nesse quesito, com cerca de metade dos entrevistados se declarando insatisfeita e a outra metade satisfeita - muito poucos disseram não saber ou se declararam indiferentes (Gráfico 4). É notório, no entanto, a correlação entre o nível de satisfação e o resultado obtido no processo - os mais insatisfeitos são aqueles que perderam a ação (cerca de $80 \%$ deles se declararam insatisfeitos), depois os que ainda estão esperando pelo desfecho do caso (cerca de $70 \%$ ), e poucos dos que ganharam a ação se declararam insatisfeitos (cerca de $20 \%$ ). 


\section{Gráfico 4}

Entrevistados de acordo com satisfação com a justiça (\%)

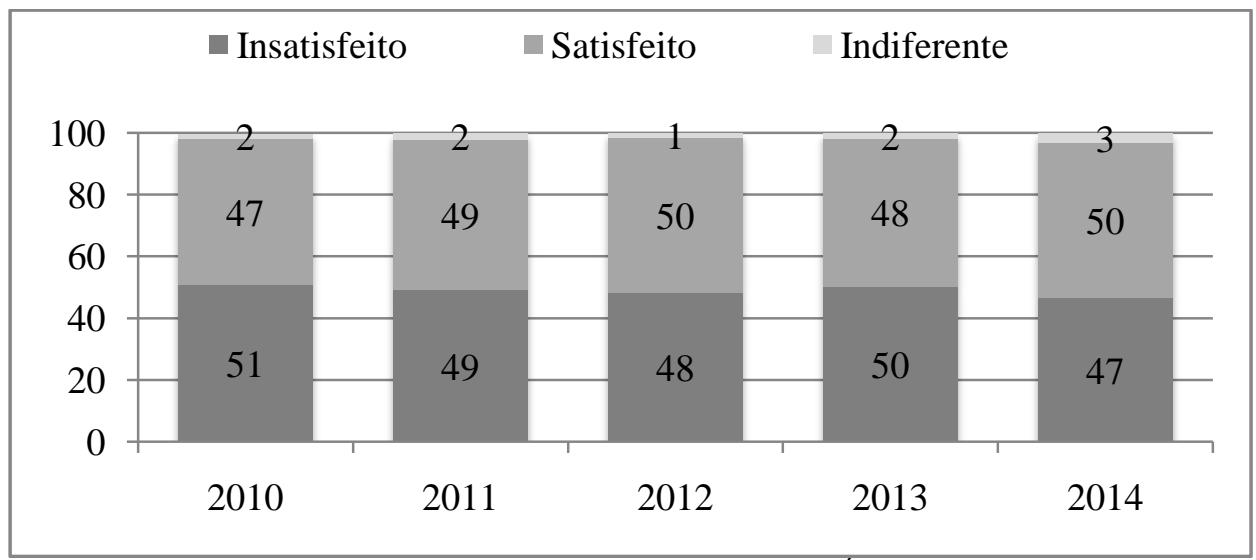

Fonte: Elaboração própria com base em dados do survey Índice de Confiança na Justiça no Brasil, FGV (2010-2014).

Base: 2010: 2.117 entrevistas; 2011: 3.044 entrevistas; 2012: 3329 entrevistas; 2013: 3.057 entrevistas; 2014: 2.027 entrevistas.

Ainda no âmbito das instâncias e processos formais, perguntamos aos entrevistados sobre acesso a serviços jurídicos, como os de advogados [O(a) Sr.(a) ou alguém do seu domicílio já consultou um advogado?]. Ao longo dos anos, a maioria dos entrevistados relatou já ter consultado um advogado (pessoalmente ou outro membro do domicílio), e os percentuais destes variaram entre $62 \%$ e $69 \%$ (Gráfico 5). Aos que disseram ter consultado advogado, perguntamos se a consulta se deu de forma particular ou via serviços providos pelo Estado [Esse advogado era particular ou da Defensoria Pública?], ao que a maioria (entre $73 \%$ e $88 \%$ ) respondeu ser particular (Gráfico 6).

\section{Gráfico 5}

\section{Entrevistados que declararam ter consultado advogado (\%)}

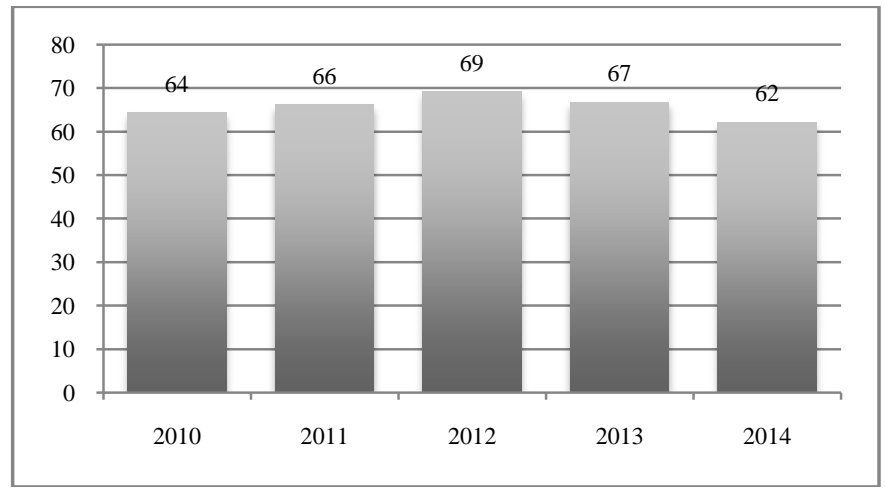

Fonte: Elaboração própria com base em dados do survey Índice de Confiança na Justiça no Brasil, FGV (2010-2014). Base: 2010: 4.685 entrevistas; 2011: 6.213 entrevistas; 2012: 6.509 entrevistas; 2013: 6.629 entrevistas; 2014: 4.973 entrevistas. 


\section{Gráfico 6 \\ Entrevistados que declararam ter consultado advogado por tipo (particular ou defensoria pública) (\%)}

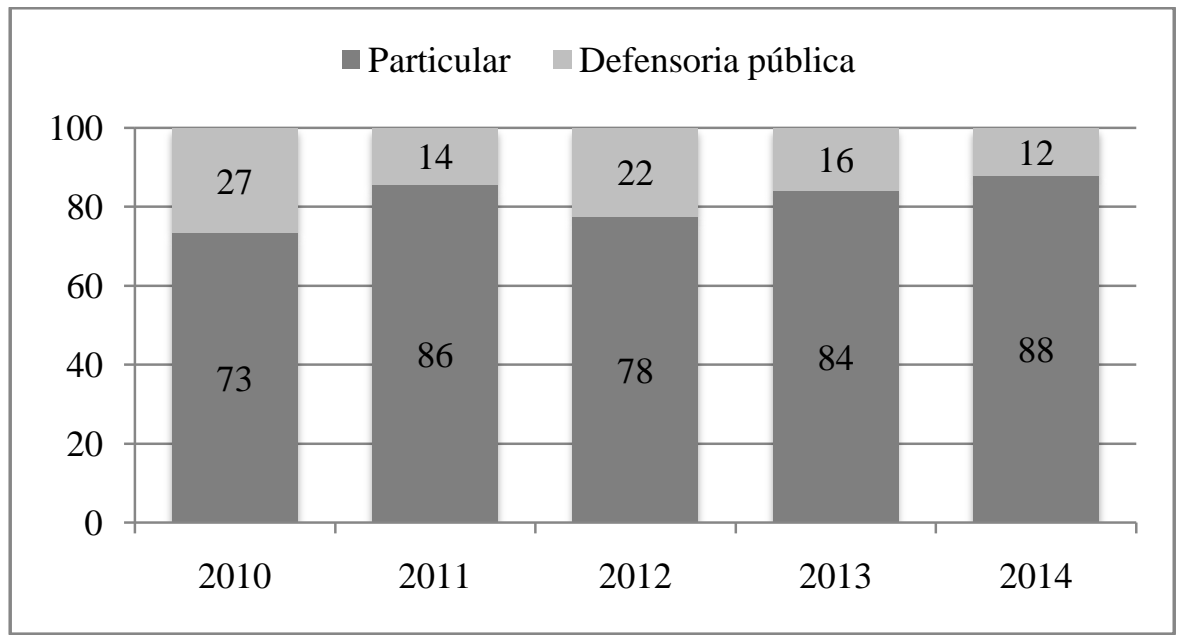

Fonte: Elaboração própria com base em dados do survey Índice de Confiança na Justiça no Brasil, FGV (2010-2014).

Base: 2010: 3.013 entrevistas; 2011: 4.108 entrevistas; 2012: 4.499 entrevistas;

2013: 4.205 entrevistas; 2014: 3.090 entrevistas.

Outra instituição formal de acesso à justiça, embora extrajudicial, que nos interessa investigar é o Procon. As pessoas conhecem essa instituição? Já utilizaram? Conseguiram resolver seu conflito via Procon? Ficaram satisfeitas com a experiência? [O(a) Sr.(a) conhece ou já ouviu falar da Fundação de Proteção e Defesa do Consumidor, ou Procon?. Para os que declararam conhecer, perguntamos: O (a) Sr.(a) já utilizou os serviços do Procon?. Aos que utilizaram, solicitamos que respondessem: $O(a)$ Sr.(a) conseguiu resolver seu problema via Procon? e Em relação ao seu nível de satisfação com o Procon, o(a) Sr.(a) diria que está (LER OPÇÕES): 1. Muito insatisfeito; 2. Um pouco insatisfeito; 3. Um pouco satisfeito; 4. Muito satisfeito]. 


\section{Gráfico 7 \\ Entrevistados que declararam conhecer e já ter utilizado Procon (\%)}

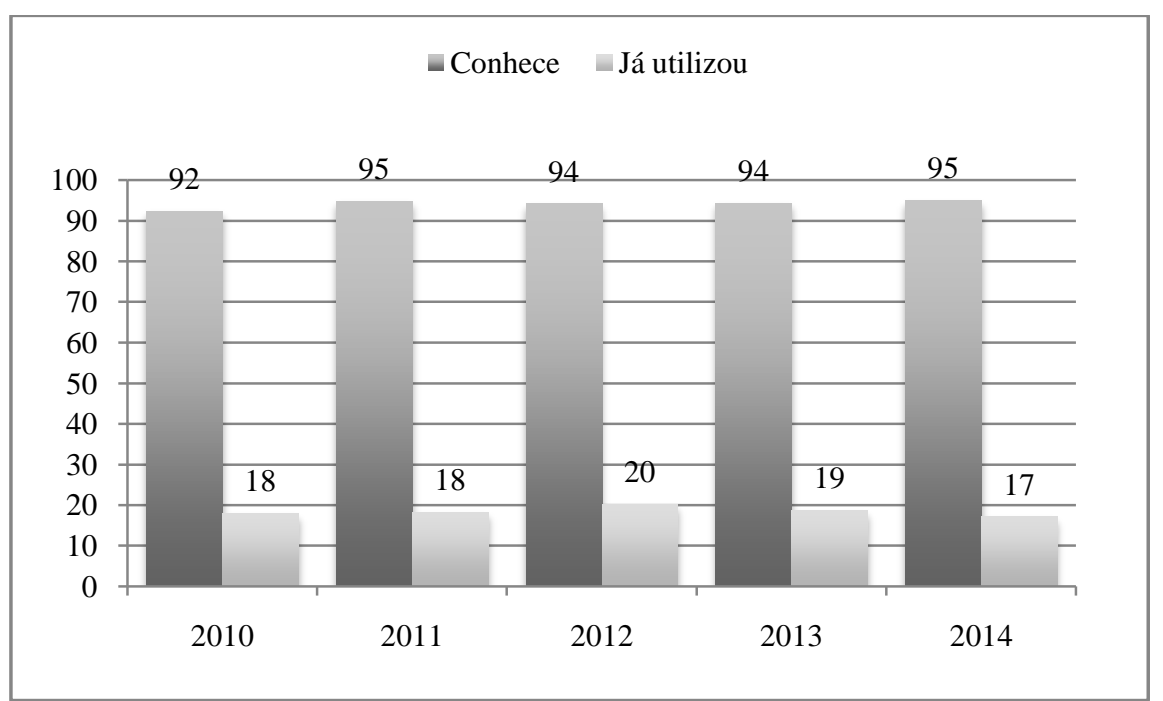

Fonte: Elaboração própria com base em dados do survey Índice de Confiança na Justiça no Brasil, FGV (2010-2014).

Base: 2010: 4.685 entrevistas; 2011: 6.213 entrevistas; 2012: 6.509 entrevistas; 2013: 6.629 entrevistas; 2014: 6.623 entrevistas.

\section{Gráfico 8}

Entrevistados de acordo com satisfação com o Procon (\%)

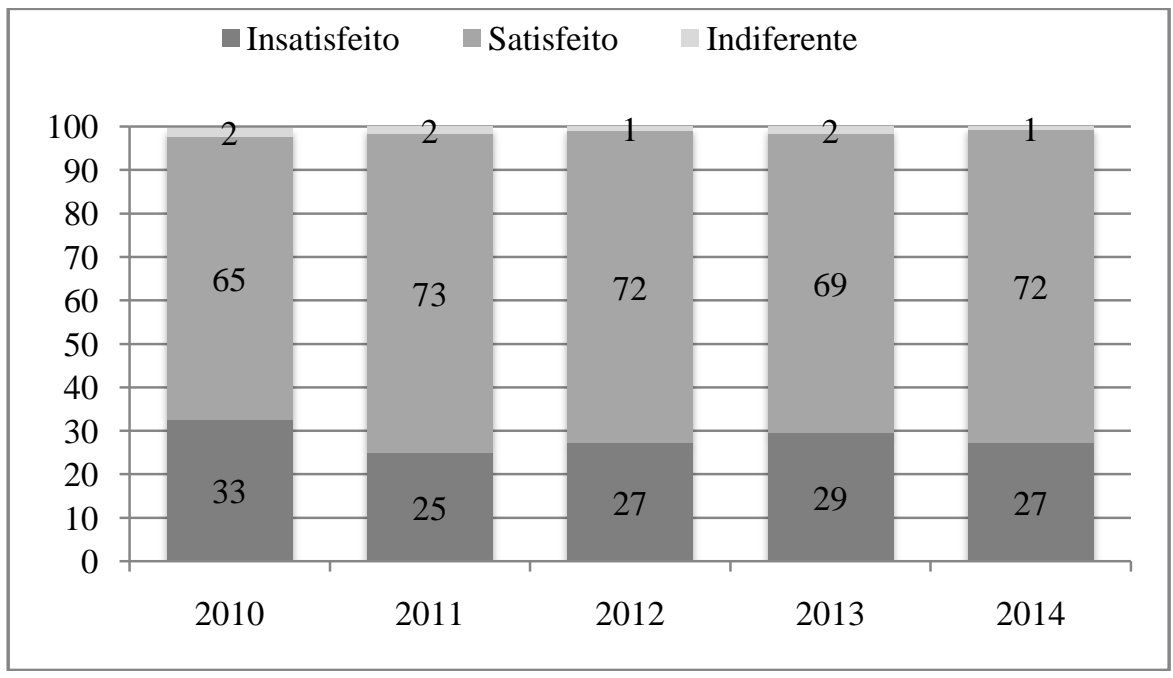

Fonte: Elaboração própria com base em dados do survey Índice de Confiança na Justiça no Brasil, FGV (2010-2014).

Base: 2010: 4.685 entrevistas; 2011: 6.213 entrevistas; 2012: 6.509 entrevistas; 2013: 6.629 entrevistas; 2014: 6.623 entrevistas. 
A grande maioria dos entrevistados conhece ou já ouviu falar do Procon, e cerca de dois quintos já utilizaram os serviços da instituição (Gráfico 7). A maioria dos usuários obteve resolução do problema (os percentuais variam de $65 \%$ a $70 \%$ ), sendo que a maior parte se declarou satisfeita com a experiência (Gráfico 8). Novamente, observamos uma forte correlação entre nível de satisfação e resultado obtido - os que não conseguiram resolução ficaram mais insatisfeitos $(60 \%)$, e apenas $8 \%$ dos que conseguiram solução para seu problema se declaram insatisfeitos. A pergunta relacionada ao Procon serve para que possamos verificar formas de solução de conflito que dispensam a entrada no sistema de justiça estatal, uma vez que esse órgão está ligado aos poderes executivos estaduais.

De maneira geral, os resultados obtidos até aqui vão ao encontro das considerações de Sadek (2014), ao afirmar que, apesar da Constituição de 1988 reconhecer, há quase três décadas, um amplo rol de direitos sociais, civis e políticos, a capacidade de vivência e reivindicação desses direitos é pouco igualitária.

No que diz respeito aos indicadores subjetivos de acesso à justiça em sentido substantivo, trabalhamos de duas formas. Primeiro, seguindo a proposta comum nos estudos anteriormente abordados, de identificar situações potencialmente conflitivas e mapear potenciais conflitos vividos e a trajetória escolhida para sua solução. Segundo, verificando o nível de conhecimento que as pessoas têm acerca dos direitos formais, pois, como observamos na literatura de referência, esse conhecimento é uma das chaves para que possam dar sentido às experiências vivenciadas como desrespeito a direitos e, portanto, torná-las passíveis de resolução e reivindicação pela via legal.

Para o mapeamento da vivência de conflitos e a trajetória de resolução adotada, apresentamos situações de conflito comuns, investigamos sua incidência e o tipo de solução buscada. Elegemos, inicialmente, três esferas de conflitos potencialmente jurídicos: consumo, trabalho e trânsito. Primeiro investigando apenas a busca por instituições formais de justiça e, depois, pontualmente, outras formas de resolução adotadas. Essa formulação nos permite identificar a incidência de conflitos e a proporção deles que se tornam litígios. [Gostaria agora que o(a) Sr.(a) me dissesse se o(a) Sr.(a) ou alguém do seu domicílio já passou por alguma dessas situações que eu vou citar: 1. Recebeu cobrança abusiva por parte de alguma empresa (telefonia, banco, ou loja) e não conseguiu resolver o problema com a empresa; 2. Perdeu o emprego e não recebeu o que lhe era devido e não conseguiu acordo com o empregador; 3. Teve um acidente de trânsito (batida/atropelamento) e não conseguiu resolver o problema com o outro envolvido. E para as situações em que o entrevistado responde positivamente, perguntamos: E o(a) Sr.(a) (ou a pessoa que passou por isso) procurou a justiça para solucionar este problema ou não?].

Observamos que os conflitos de consumo são mais comuns, com aproximadamente um quarto dos entrevistados declarando já ter passado por algum conflito de cobrança abusiva por produtos ou serviços (Gráfico 9). Mas a maioria dos que enfrentam problemas de direito do consumidor não procura o caminho da justiça formal. 


\section{Gráfico 9 \\ Entrevistados que declararam ter vivenciado conflito (\%), e entrevistados que declararam ter procurado a justiça por área do conflito (\%)}

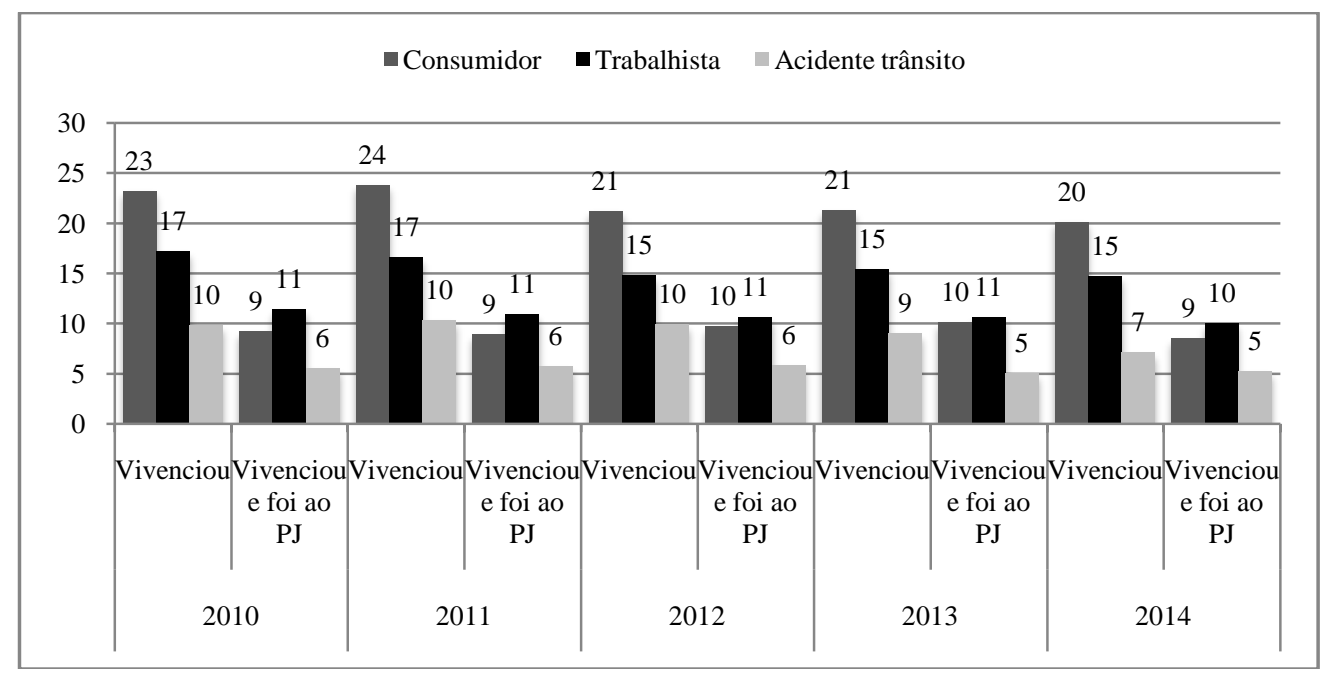

Fonte: Elaboração própria com base em dados do survey Índice de Confiança na Justiça no Brasil, FGV (2010-2014).

Base: 2010: 4.685 entrevistas; 2011: 6.213 entrevistas; 2012: 6.509 entrevistas; 2013: 6.629 entrevistas; 2014: 6.623 entrevistas.

$* \mathrm{PJ}=$ Poder Judiciário.

Já os conflitos trabalhistas foram vivenciados por cerca de $15 \%$ dos entrevistados, e nesse caso a busca pela via da justiça formal é mais frequente, com a maioria recorrendo ao Judiciário. E, por fim, problemas de trânsito, com incidência de cerca de $10 \%$, são casos em sua maioria não levados à justiça.

A todos aqueles que vivenciaram o problema e não procuraram a justiça, indagamos o motivo de não considerarem essa via [Por que não procurou a justiça?]. As respostas, espontâneas, foram codificadas posteriormente, e nos três casos a principal justificativa é a morosidade para resolver o problema via Judiciário (incidência de $25 \%$ a $30 \%)$. A segunda justificativa mais comum é que não precisaram ir à justiça, pois conseguiram resolver o problema de outra forma (de $20 \%$ a $25 \%$ ). E, em terceiro lugar, está a afirmação de que não sabiam ser possível procurar a justiça para o tipo de problema vivenciado ou então que não sabiam como usar essa via (de $10 \%$ a $15 \%$ ). A alegação de que o custo do acesso ao Judiciário é alto aparece em quarto lugar (de $10 \%$ a $12 \%$ ). De maneira geral, essas respostas se aproximam das encontradas em pesquisas anteriores (IBGE e Ipea, já referenciadas).

Uma vez que essa forma de perguntar mapeia apenas o caminho formal de resolução, buscamos ampliar o escopo dessa medida expandindo a lista de situações e também os possíveis caminhos de gestão de conflitos. Assim, passamos a utilizar a metodologia das pesquisas de eventos judicializáveis, combinada à abordagem do processamento de disputas, apresentando aos entrevistados uma lista de 12 situações 
conflitivas $^{12}$, indagando se vivenciaram tais situações, e, para cada situação que o entrevistado declara ter enfrentado nos últimos 12 meses, perguntamos sobre a resposta escolhida [Vou mencionar uma série de tipos de problemas ou conflitos e gostaria que o(a) Sr.(a) me dissesse se passou por isso pessoalmente nos últimos 12 meses. Para cada situação vivenciada, perguntamos: E o(a) Sr.(a) tentou ou não buscar solução para seu conflito?. Se tentou, perguntamos: Qual foi a solução buscada?]. O diferencial em nossa forma de abordar a questão é que tomamos o cuidado de não inferir que a busca por algum tipo de solução seja o caminho esperado, deixando explícita a possibilidade de inação.

Os conflitos mais recorrentes são os relativos a consumo, saúde, vizinhança, família e trabalhista (Tabela 4). E o tipo de conflito a que as pessoas estão mais sujeitas tem alguma relação com renda e escolaridade - por exemplo, os conflitos de consumo são mais frequentes em faixas de renda e escolaridade mais altas, e os de família, um pouco mais frequentes nas faixas de renda e escolaridade mais baixas.

Tabela 4

Vivência de conflitos, de acordo com renda domiciliar e escolaridade (\%)

\begin{tabular}{|c|c|c|c|c|c|c|c|c|c|}
\hline & \multirow[b]{2}{*}{ Total } & \multicolumn{5}{|c|}{ Faixas de renda domiciliar } & \multicolumn{3}{|c|}{ Escolaridade } \\
\hline & & $\begin{array}{l}\text { Até } 1 \\
\text { SM }\end{array}$ & $\begin{array}{l}+1 a 4 \\
\text { SM }\end{array}$ & $\begin{array}{l}+4 a 8 \\
\text { SM }\end{array}$ & $\begin{array}{l}+8 a 12 \\
\text { SM }\end{array}$ & $\begin{array}{l}+12 \\
\text { SM }\end{array}$ & Baixa & Média & Alta \\
\hline $\begin{array}{l}\text { Consumo: } \\
\text { cobrança } \\
\text { abusiva } \\
\text { telefonia }\end{array}$ & 18 & 9 & 19 & 15 & 19 & 31 & 14 & 20 & 30 \\
\hline Saúde pública & 12 & 13 & 14 & 12 & 8 & 4 & 14 & 12 & 3 \\
\hline $\begin{array}{l}\text { Consumo: } \\
\text { cobrança } \\
\text { abusiva banco }\end{array}$ & 9 & 4 & 8 & 8 & 11 & 17 & 6 & 12 & 14 \\
\hline Vizinhança & 8 & 8 & 7 & 6 & 14 & 10 & 6 & 9 & 11 \\
\hline Família & 6 & 11 & 6 & 6 & 2 & 4 & 6 & 7 & 2 \\
\hline $\begin{array}{l}\text { Consumo: } \\
\text { produto } \\
\text { avariado }\end{array}$ & 6 & 6 & 5 & 8 & 5 & 11 & 5 & 7 & 11 \\
\hline Trabalhista & 4 & 3 & 4 & 3 & 2 & 7 & 3 & 4 & 4 \\
\hline Plano de saúde & 4 & 1 & 3 & 5 & 7 & 10 & 2 & 5 & 10 \\
\hline
\end{tabular}

\footnotetext{
${ }^{12}$ As situações foram apresentadas da seguinte maneira: "a) Passou por algum conflito de família, como separação, divórcio, guarda dos filhos, pensão alimentícia? b) Teve algum conflito com vizinhos, por causa de barulho, reforma, lixo? c) Teve algum problema com a previdência social, seja referente a aposentadoria, pensão, seguro desemprego, licença médica? d) Teve algum problema trabalhista, como, por exemplo, recebimento de valores devidos pelo empregador, demissão sem justa causa, recebimento de horas extra? e) Teve algum problema relacionado a imóveis ou terra - questão de despejo, desocupação, disputa por posse, recebimento de valores devidos? f) Precisou de atendimento médico gratuito e não conseguiu? g) Comprou algum produto que veio com defeito e não conseguiu trocar ou devolver? h) Teve algum problema com relação ao cumprimento do contrato com o plano de saúde, como, por exemplo, conseguir consulta, atendimento médico, ou precisou de algum procedimento ou exame e o plano se recusou a cobrir? i) O(a) Sr.(a) recebeu alguma cobrança indevida por parte de empresa de telefonia - por exemplo, de valores já pagos, por serviços não solicitados, de valores a mais do que o utilizado? j) Teve algum problema com instituição financeira ou bancária - como, por exemplo, cobranças indevidas de taxas e juros por serviços não solicitados? k) Sofreu agressão física ou ameaça? I) Recebeu cobrança de luz indevida (valores já pagos ou superiores ao utilizado)?".
} 


\begin{tabular}{|l|c|c|c|c|c|c|c|c|c|}
\hline & \multirow{2}{*}{ Total } & \multicolumn{5}{|c|}{ Faixas de renda domiciliar } & \multicolumn{3}{c|}{ Escolaridade } \\
\cline { 3 - 10 } & $\begin{array}{l}\text { Até 1 } \\
\text { SM }\end{array}$ & $\begin{array}{l}\mathbf{+ 1 a 4} \\
\text { SM }\end{array}$ & $\begin{array}{l}\mathbf{+ 4 a 8} \\
\text { SM }\end{array}$ & $\begin{array}{l}\mathbf{+ 8 a 1 2} \\
\text { SM }\end{array}$ & $\begin{array}{l}\mathbf{+ 1 2} \\
\text { SM }\end{array}$ & Baixa & Média & Alta \\
\hline $\begin{array}{l}\text { Consumo: } \\
\text { cobrança } \\
\text { abusiva luz }\end{array}$ & 4 & 3 & 4 & 5 & 5 & 4 & 4 & 5 & 3 \\
\hline $\begin{array}{l}\text { Previdência } \\
\text { social }\end{array}$ & 3 & 3 & 5 & 2 & 1 & 2 & 3 & 3 & 2 \\
\hline $\begin{array}{l}\text { Agressão } \\
\text { física/ameaça }\end{array}$ & 3 & 4 & 4 & 2 & 3 & 4 & 4 & 3 & 3 \\
\hline Imobiliário & 2 & 2 & 2 & 2 & 3 & 4 & 2 & 2 & 3 \\
\hline Base (n) & $\mathbf{1 6 5 0}$ & $\mathbf{1 5 7}$ & $\mathbf{7 9 0}$ & $\mathbf{4 3 8}$ & $\mathbf{1 0 9}$ & $\mathbf{1 5 6}$ & $\mathbf{8 8 4}$ & $\mathbf{5 4 2}$ & $\mathbf{2 2 3}$ \\
\hline
\end{tabular}

Fonte: Elaboração própria com base em dados do survey Índice de Confiança na Justiça no Brasil, FGV (2014).

Já a busca por solução sofre influência sobretudo do tipo de conflito, embora também haja algum efeito de renda e escolaridade nessa escolha. Os conflitos que as pessoas menos declararam buscar resolver (Tabela 5) são aqueles ligados ao atendimento de saúde (63\% das pessoas que passaram por esse problema não buscaram solução, e a maior parte dos que tentaram resolver o fizeram pagando pelo serviço).

O segundo tipo de conflito que as pessoas mais "deixam pra lá" é a agressão física (43\%), sendo que quando se busca solução, a polícia é o caminho mais frequente (39\% dos casos).

Tabela 5

Solução procurada de acordo com conflito (\%)

\begin{tabular}{|c|c|c|c|c|c|c|c|c|c|c|c|c|}
\hline & 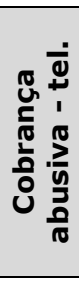 & 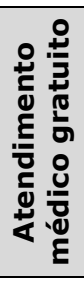 & 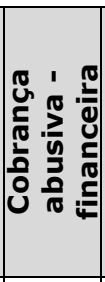 & 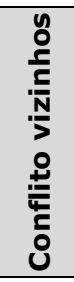 & 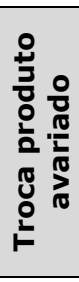 & 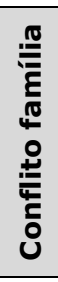 & 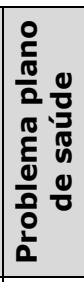 & 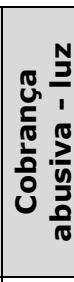 & 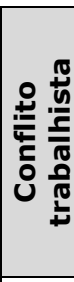 & 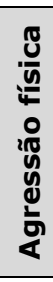 & $\begin{array}{l}\frac{\pi}{0} \\
\frac{\pi}{0} \\
\frac{\pi}{0} \\
\frac{\pi}{3} \\
\frac{0}{0} \\
\frac{0}{2}\end{array}$ & 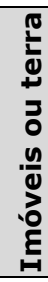 \\
\hline Outra parte & 61 & 17 & 54 & 40 & 40 & 15 & 56 & 46 & 18 & 5 & 30 & 24 \\
\hline Não procurou solução & 17 & 63 & 21 & 15 & 29 & 33 & 30 & 32 & 25 & 43 & 9 & 24 \\
\hline Judiciário & 4 & 1 & 7 & 3 & 6 & 25 & 1 & 4 & 48 & 7 & 35 & 38 \\
\hline Defensoria Pública & - & 1 & - & - & 1 & 7 & - & - & 2 & 4 & 4 & 3 \\
\hline Procon & 5 & - & 3 & - & 6 & - & 3 & 4 & - & - & - & 3 \\
\hline Polícia & - & 1 & - & 33 & - & 3 & - & - & - & 39 & - & - \\
\hline Outro & 14 & 19 & 15 & 9 & 18 & 16 & 10 & 13 & 6 & 2 & 22 & 9 \\
\hline Base (n) & 298 & 197 & 145 & 124 & 104 & 99 & 71 & 71 & 60 & 56 & 54 & 34 \\
\hline
\end{tabular}

Fonte: Elaboração própria com base em dados do survey Índice de Confiança na Justiça no Brasil, FGV (2014). 
Nos conflitos de consumo, a solução mais buscada é a tentativa de negociação direta com a outra parte envolvida, visando a um acordo com as empresas. Os conflitos de vizinhança também seguem em grande parte esse caminho, sendo a polícia o segundo recurso mais acionado.

O Judiciário é o caminho mais recorrente quando se trata de conflitos trabalhistas, ou conflitos ligados à previdência social e à propriedade de terras ou imóveis. A Defensoria Pública é recurso pouco mencionado, sendo mais comum em casos de família (7\%). Assim, percebemos que diferentes tipos de conflitos exibem diferentes padrões de gestão.

Considerando que o desconhecimento dos cidadãos acerca de seus direitos e

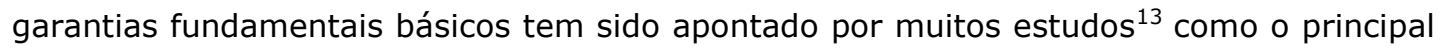
entrave no acesso à justiça, acarretando o desconhecimento sobre os mecanismos jurisdicionais e extrajudiciais, consideramos importante investigar o quanto os brasileiros sabem sobre a lei, seus direitos e deveres.

Para isso perguntamos aos entrevistados se saberiam dizer algum direito que tenham garantido por lei [Dizem que a lei brasileira dá muitos direitos para as pessoas. O(a) Sr.(a) saberia ou não dizer algum desses direitos?], e, para aqueles que disseram sim, solicitamos que especificassem quais direitos conheciam. Indagamos também acerca do conhecimento de deveres previstos em lei [A lei brasileira também impõe deveres às pessoas. O(a) Sr.(a) saberia ou não dizer algum desses deveres?], e àqueles que deram respostas positivas, solicitamos que especificassem os deveres previstos em lei que conhecem.

\section{Gráfico 10}

\section{Entrevistados que disseram conhecer direitos e deveres previstos nas leis brasileiras (\%)}

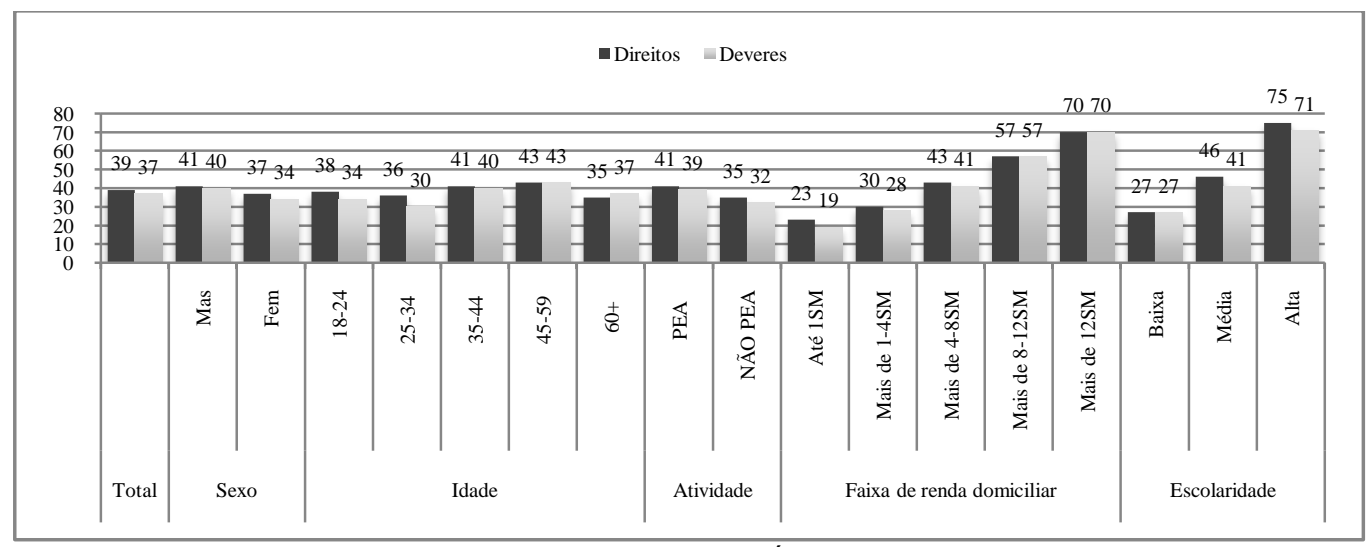

Fonte: Elaboração própria com base em dados do survey Índice de Confiança na Justiça no Brasil, FGV (2014).

Base: 1.650 entrevistas, julho-setembro de 2014.

\footnotetext{
13 Ver, entre outros, Grinover, Dinamarco e Watanabe (1988); Faria (1989); Genn e Paterson (2001); Albiston e Sandefur (2013).
} 
MEDINDO O ACESSO À JUSTIÇA CÍVEL NO BRASIL

O que observamos foi a absoluta falta de conhecimento das pessoas com relação aos seus direitos: $61 \%$ do total de entrevistados não souberam citar sequer um direito previsto em lei. O mesmo se aplica aos deveres, com $63 \%$ não sabendo citar um dever perante a lei. Notamos que o desconhecimento é maior entre os mais jovens (até 34 anos) e os mais idosos (acima de 60 anos), e também fortemente influenciado pela renda e pela escolaridade, ou seja, quanto mais baixa a renda e a escolaridade, maior o desconhecimento.

O cenário que encontramos em 2014 não difere muito do encontrado em pesquisa do CPDOC no final da década de 1990 (Pandolfi et al., 1999). Ao solicitar aos entrevistados em um survey, conduzido na região metropolitana do Rio de Janeiro, que enumerassem três dos mais importantes direitos dos brasileiros, 56,7\% dos entrevistados não souberam mencionar ao menos um direito garantido aos cidadãos. Entre os que souberam citar algum direito, os direitos sociais foram os mais mencionados (lembrados por $28,5 \%$ dos entrevistados), seguidos dos civis $(11,7 \%)$ e dos políticos $(1,6 \%)$.

Se em termos do volume de desconhecimento de direitos a realidade não mudou, o tipo de direito mencionado por aqueles que souberam dizer algum direito mudou. Em 2014 os mais lembrados foram os direitos relativos às liberdades: de expressão, de pensamento, de locomoção e de reunião, enumeradas por $46 \%$ daqueles que souberam citar direitos. Em segundo lugar, com $20 \%$ de menções, vieram os direitos à saúde e à educação. Em terceiro, os direitos trabalhistas, mencionados por $14 \%$ dos entrevistados.

Já com relação aos deveres, os mais lembrados foram o respeito às leis (38\%), o respeito ao próximo (32\%), o voto $(27 \%)$ e o cumprimento das obrigações fiscais e tributárias (26\%).

\section{Gráfico 11}

\section{Direitos citados (\%)}

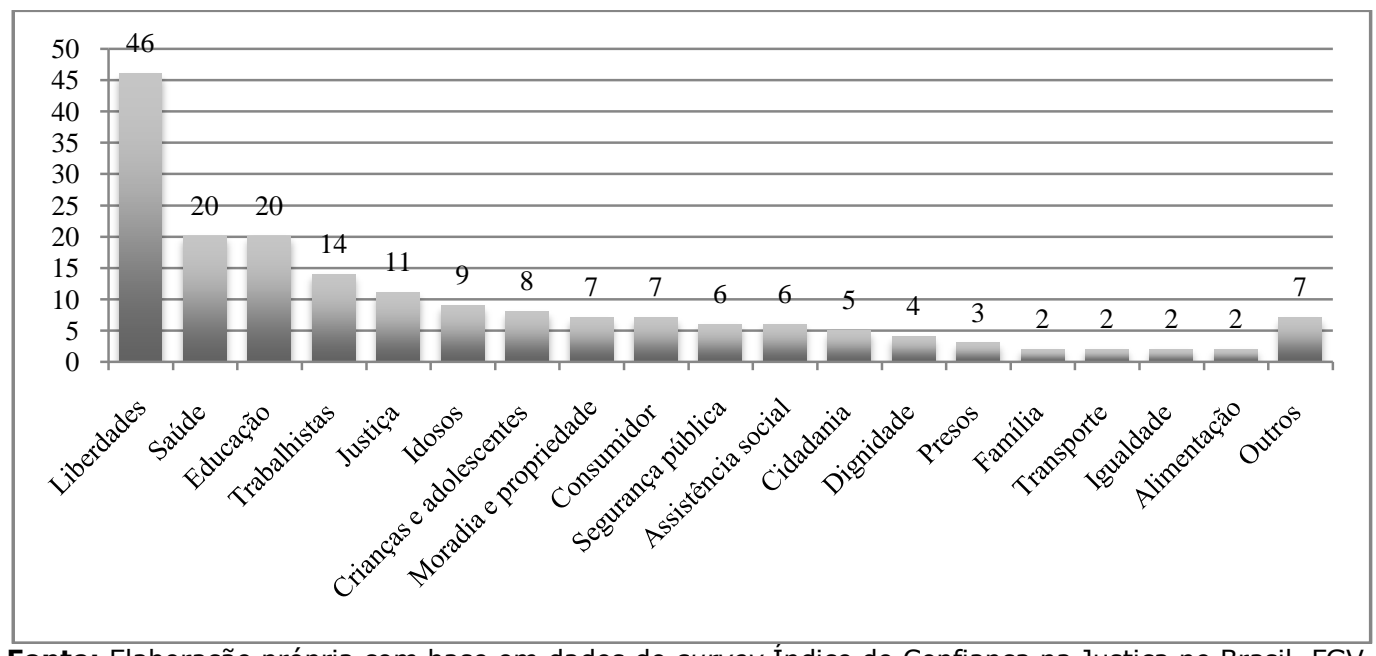

Fonte: Elaboração própria com base em dados do survey Índice de Confiança na Justiça no Brasil, FGV (2014).

Base: 645 entrevistados que mencionaram algum direito, julho-setembro de 2014. 
Gráfico 12

Deveres citados (\%)

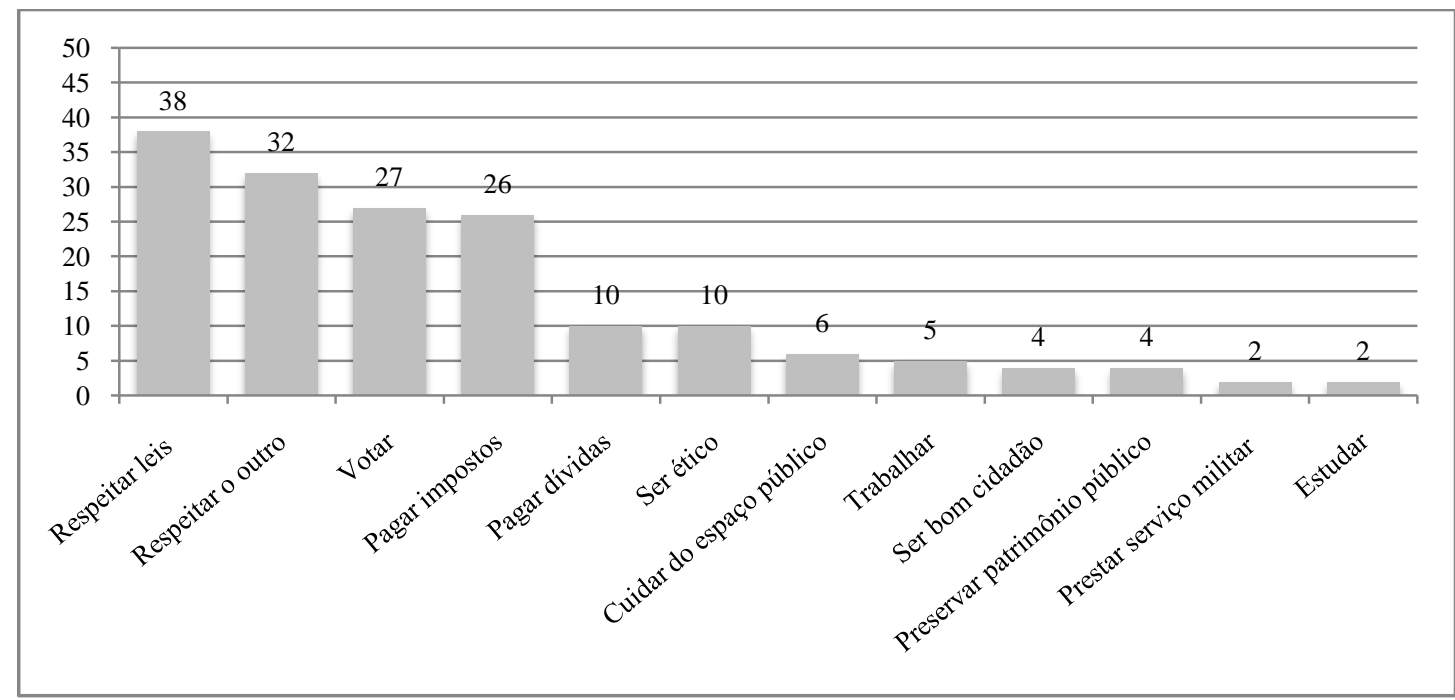

Fonte: Elaboração própria com base em dados do survey Índice de Confiança na Justiça no Brasil, FGV (2014). Base: 608 entrevistados que mencionaram algum dever, julho-setembro de 2014.

Diante dessas evidências, é importante questionar: como esperar que as pessoas reivindiquem seus direitos ou busquem nas instituições formais de justiça apoio para a gestão de conflitos, se pouco conhecem esses direitos, e mesmo os deveres, de cidadania? Se consideramos o acesso à justiça a partir da abordagem do processo de "nomeação, responsabilização (culpabilização) e reivindicação", nesse cenário de desconhecimento de direitos, podemos pensar que o entrave, ou a principal barreira, no acesso à justiça pode estar no próprio reconhecimento da situação vivenciada como prejudicial.

\section{Considerações finais}

Buscamos neste artigo mapear estudos e metodologias empregados para mensurar acesso à justiça, focados na vivência de conflitos potencialmente jurídicos, atentando para a demanda por equipamentos de justiça e o uso destes, como forma de gestão desses conflitos. Demarcamos nosso interesse nos indicadores subjetivos de acesso à justiça, produzidos via survey. E, uma vez que esses indicadores subjetivos cobrem tanto comportamento quanto valores e atitudes, delimitamos a discussão apenas aos indicadores de comportamento.

Nosso objetivo não foi explicar o acesso à justiça, e sim documentar criticamente o que aprendemos até aqui sobre mensuração e construção de indicadores de comportamento de acesso à justiça, atentando para as limitações que enfrentamos e como podemos contorná-las, sobretudo no que diz respeito à validade de construto das 
MEDINDO O ACESSO À JUSTIÇA CÍVEL NO BRASIL

medidas, ou seja, às formas de perguntar (elaboração das perguntas) e aos filtros utilizados na delimitação do que é acesso à justiça.

Com isso, testamos diferentes formas de dar conta dessa medida, e das implicações de cada uma dessas formas, e propusemos uma medida síntese, combinando elementos de três linhas predominantes na busca por mensurar o comportamento das pessoas em relação ao acesso à justiça: necessidades legais, processamento de disputas e eventos judicializáveis.

A principal crítica que tecemos à forma como os indicadores subjetivos de acesso à justiça vêm sendo construídos no Brasil é a ênfase na vivência de situações potencialmente conflitivas, a partir do emprego de filtros de trivialidade. E propusemos uma medida abordando as diferentes dimensões de acesso, invertendo a prioridade das situações e incorporando a dimensão da busca efetiva das instituições e o conhecimento de direitos.

O que aprendemos com base na revisão da literatura, dos estudos desenvolvidos até aqui e das nossas próprias medidas é que uma boa medida de acesso à justiça passa por diferentes dimensões do conceito, sendo que o contexto social importa para a compreensão da trajetória dos conflitos potencialmente judicializáveis. Em nossa proposta utilizamos as dimensões de experiência direta com o Judiciário, identificando o tipo de Judiciário utilizado, a vivência de conflitos potencialmente jurídicos e o caminho perseguido para sua resolução.

Assim como é notado nos contextos norte-americano e europeu, observamos que no Brasil também a grande maioria dos potenciais conflitos judicializáveis não chega às instituições formais de justiça, sendo que diferentes tipos de disputas exibem diferentes padrões de resolução.

Verificamos no rol de problemas potencialmente judicializáveis vivenciados pelo público que os de maior incidência são os ligados ao universo do consumo, e são também os que menos são levados às instituições formais de justiça. Ao mesmo tempo, quando exploramos diretamente a busca do Poder Judiciário, verificamos que pouco mais de dois quintos dos entrevistados afirmam já ter recorrido a essa instância de gestão de conflitos (pessoalmente ou alguém residente no domicílio), sendo os conflitos de consumo o segundo motivo que mais leva as pessoas à justiça, estando atrás apenas das questões de trabalho.

Dessa forma, fica explícito que o fenômeno mensurado é diferente a depender da ênfase dada, se no conflito ou na busca das instituições, uma vez que as pessoas reagem de formas diversas a diferentes tipos de situações potencialmente conflitivas. Se o que nos interessa mensurar é o uso e o acesso às instituições formais de justiça, é fundamental perguntar sobre a busca do Poder Judiciário. Mas, uma vez que existem outras formas de gestão de conflitos que não a via judicial, a abordagem combinada a eventos judicializáveis é indispensável, sendo, no entanto, preciso atentar tanto para o tipo de filtragem utilizada (trivialidade $\mathrm{x}$ lista de problemas potencialmente judicializáveis) quanto para a formulação da questão. É evidente que toda medida implica 
um recorte da realidade e impõe limitações, assim, o que propomos é uma medida que visa reduzir essas limitações, combinando diferentes dimensões.

Como afirmam Albiston e Sandefur (2013) para o contexto norte-americano, também no caso do Brasil notamos que é uma pequena fração dos problemas potencialmente jurídicos na paisagem social de disputas na área cível que chega ao Judiciário. As pessoas não costumam concebê-los como problemas de justiça civil, pois muitas vezes elas não os elaboram como um problema legal, mas como um problema social, privado, ou até mesmo de má sorte (Albiston e Sandefur, 2013, p. 118).

Afirmamos com os autores que é preciso trabalhar o acesso à justiça como uma demanda universal, não restrita àqueles que dispõem de meios financeiros para reivindicar seus direitos, investigando, assim, as barreiras existentes para além da falta de recursos financeiros, que dizem respeito principalmente aos significados sociais construídos e à dificuldade de compreender um problema como um problema legal. É preciso considerar o nível de (des)conhecimento de direitos e deveres e da linguagem de direitos. Daí porque, apesar de já existirem pesquisas que envolvam vitimização ou experiência com a justiça, como as documentadas no artigo, é necessário incorporar a essas medidas outras dimensões como a disposição ou não de acessar a justiça, outros mecanismos de gestão e formas de solução dos conflitos, no âmbito civil, além do conhecimento de direitos (e deveres), como propusemos.

Fabiana Luci de Oliveira - Professora do Departamento de Sociologia da UFSCar. Bolsista Produtividade do CNPq. Doutora em Ciências Sociais pela UFSCar, com pósdoutorado em Ciência Política pela USP. E-mail: <fabianaluci@ufscar.br>.

Luciana Gross Cunha - Coordenadora do Centro de Pesquisa Jurídica Aplicada e professora em período integral da Escola de Direito da FGV SP. Mestre e doutora em Ciência Política pela USP. E-mail: <luciana.cunha@fgv.br>.

\section{Referências bibliográficas}

Albiston, C. R.; SANDefuR, R. L. "Expanding the empirical study of access to justice". Wisconsin Law Review, n 101, p. 101-120, 2013.

Cappelletti M.; Garth, B. Acesso à justiça. Porto Alegre: Fabris, 1988 [1978].

CunHA, L. G., et al. Índice de confiança na justiça. Relatório do Ano 4 ( $2^{\circ}$ trimestre/2012 ao $1^{\circ}$ trimestre/2013).

CURRAn, B. A. The legal needs of the public: the final report of a national survey. Chicago: American Bar Foundation, 1977.

FARIA, J. E. (org.). Direito e justiça: a função social do Judiciário. São Paulo: Ática, 1989.

Felstiner, W. L. F.; ABeL, R. L.; SARAT, A. "The emergence and transformation of disputes: naming, blaming, claiming". Law and Society Review, vol. 15, p. 631-654, 1980. 
MEDINDO O ACESSO À JUSTIÇA CÍVEL NO BRASIL

Genn, H. Paths to justice: what people do and think about going to law. Oxford: Hart Publishing, 1999.

GenN, H.; Paterson, A. Paths to justice Scotland: what people in Scotland think and do about going to law. Oxford: Hart Publishing, 2001.

Grinover, A. P, Dinamarco, C.; Watanabe, K. (orgs.). Participação e processo. São Paulo: Revista dos Tribunais, 1988.

Grossman, J. B.; TRUBeK, D. M. (orgs.). "Special issue on dispute processing and civil litigation". Law \& Society Review, vol. 15, n 391, p. 395-399, 1980-1981.

JUNQUEIRA, E. "Acesso à justiça: um olhar retrospectivo". Revista Estudos Históricos, vol. 9, n 18, p. 389-402, 1996.

MARKS, F. "Some research perspectives for looking at legal need and legal services delivery systems: old forms or new?". Law \& Society Review, vol. 11, n 191, p. 191-205, 1976.

PANDolfi, D. C., et al. Cidadania, justiça e violência. Rio de Janeiro: Editora Fundação Getúlio Vargas, 1999.

SAdEK, M. T. A Justiça Eleitoral e a consolidação da democracia no Brasil. São Paulo: Fundação Konrad Adenauer, 1994.

. O Judiciário em debate. São Paulo: Idesp/Editora Sumaré, 1995.

. "Acesso à justiça: visão da sociedade". Justitia, vol. 1, p. 271-280, 2009.

. "Acesso à justiça: um direito e seus obstáculos". Revista USP, n 101, p. 55-66, 2014.

Sadek, M. T.; Oliveira, F. L. Estudos, pesquisas e dados em justiça. In: Oliveira, F. L. (org.). Justiça em foco: estudos empíricos. Rio de Janeiro: FGV, 2012.

SAndefur, R. L. "Access to Civil Justice and race, class, and gender inequality". Annual Review of Sociology, vol. 34, p. 339-358, 2008.

SANTOS, B. S. "The law of the oppressed: the construction and reproduction of legality in Pasargada". Law and Society Review, Salt Lake City, vol. 12, n 1, p. 5-126, 1977.

\section{Pesquisas}

Características da vitimização e do acesso à justiça no Brasil. PNAD, 2009. IBGE. Disponível em: <http://www.ibge.gov.br/home/estatistica/populacao/vitimizacao_acesso_justica_2009/pnadvitimiza cao.pdf>. Acesso em: 13 set. 2015.

Sistema de Indicadores de Percepção Social (Sips). Org. Fabio Schiavinatto. Brasília: Ipea, 2011. Disponível em:

<http://repositorio.ipea.gov.br/bitstream/11058/3097/1/Livro_Sistema\%20de\%20indicadores\%20d e\%20percep\%C3\%A7\%C3\%A30\%20social\%20\%28SIPS\%29_1\%20ed.pdf>. Acesso em: 13 set. 2015. 


\section{Resumo}

\section{Medindo o acesso à Justiça Cível no Brasil}

Neste artigo mapeamos estudos e metodologias utilizados na construção de indicadores subjetivos de acesso à justiça, enfocando a vivência e a gestão de conflitos. Propomos uma medida síntese de acesso à justiça, com base na leitura crítica de tais estudos, trabalhando com uma compreensão ampla, tanto do que significa acesso à justiça quanto do que a falta de acesso implica. Essa definição compreende o acesso a uma resolução justa de conflitos, por meios idôneos (que não necessariamente a justiça estatal), levando em conta também o conhecimento dos atores acerca dos seus direitos. A discussão é feita com base em um survey conduzido entre os anos de 2010 e 2014 , cobrindo os sentidos processual e substantivo de acesso à justiça. Documentamos criticamente o estado da arte sobre mensuração e construção de indicadores de comportamento de acesso à justiça, atentando para as limitações enfrentadas e as formas de contorná-las, com ênfase na validade de construto das medidas e nos filtros utilizados na delimitação do que é acesso à justiça. Concluímos, a partir da medida proposta, que o fenômeno mensurado é diferente a depender da ênfase dada, se no conflito ou na busca das instituições, uma vez que as pessoas reagem de formas diversas a diferentes tipos de situações potencialmente conflitivas.

Palavras-chave: acesso à justiça; gestão de conflitos; indicadores subjetivos; dimensão processual; dimensão substantiva

\section{Abstract \\ Measuring access to civil justice in Brazil}

In this article, we map out studies and methodologies used to build subjective indicators of access to justice, focusing on experiences with and management of conflict. We propose a blended measure of access to justice, based on critical analysis of key studies, and work with a broad understanding of what access to justice means and what a lack of access implies. This definition includes the right to a just resolution of conflicts by any appropriate means (not necessarily via state justice) and also takes into account individuals' awareness of their rights. This work relies on survey data collected between 2010 and 2014 and covers the procedural and substantive dimensions of access to justice. We have documented state-of-the-art measurement and composition of indicators of access to justice, noting key limitations and ways to overcome them, and emphasizing construct validity and filters used in the definition of access to justice. We conclude from the proposed blended measure that, depending on where emphasis is placed-on conflict or on seeking institutional justicethe phenomenon being measured will be different, as people react in different ways to different types of potentially conflicting situations.

Keywords: access to justice; conflict management; subjective indicators; procedural dimension; substantive dimension

\section{Resumen}

La medición del acceso a la justicia civil en Brasil

En este artículo analizamos los estudios y metodologías utilizadas para construir indicadores subjetivos de acceso a la justicia, con enfoque en la experiencia del conflicto y en su gestión. Proponemos una medida síntesis de acceso a la justicia, basada en el análisis crítico de estos estudios, trabajando con una amplia comprensión de lo que significa tanto el acceso a la justicia, como a lo que implica la falta de acceso a ella. Esta definición incluye el derecho a una justa resolución de los conflictos, por los medios adecuados (no necesariamente por la justicia estatal), teniendo también en cuenta el conocimiento de los interesados sobre sus derechos. La discusión se basa en una encuesta realizada entre los años 2010-2014, que abarca la dimensión sustantiva y la dimensión procedimental del acceso a la justicia. Documentamos críticamente los avances sobre 
MEDINDO O ACESSO À JUSTIÇA CÍVEL NO BRASIL

medición y construcción de indicadores de comportamiento de acceso a la justicia, teniendo en cuenta las limitaciones que enfrentan y las maneras de conseguir superarlas, con énfasis en la validez del constructo de las medidas y los filtros utilizados en la definición de lo que es el acceso a la justicia. A partir de la medida propuesta, llegamos a la conclusión de que el fenómeno medido es diferente dependiendo del énfasis, ya sea en el conflicto o en la búsqueda de las instituciones, ya que las personas reaccionan de manera diferente a los diferentes tipos de situaciones potencialmente conflictivas.

Palabras clave: acceso a la justicia; gestión de conflictos; indicadores subjetivos; dimensión procedimental; dimensión sustantiva

\section{Résumé}

Mesure de l'accès à la justice civile au Brésil

Dans cet article, nous avons identifié les études et les méthodes utilisées pour construire des indicateurs subjectifs d'accès à la justice, en nous concentrant sur l'expérience des conflits et leur gestion. Nous proposons une mesure synthèse de l'accès à la justice, basée sur l'analyse critique de ces études, en travaillant avec une large compréhension de ce que signifie l'accès à la justice $d$ ' une part et, d'autre part, de ce qu 'implique le manque d'accès à celle-ci. Cette définition inclut le droit à une résolution équitable des conflits, par des moyens appropriés (et pas nécessairement par la justice de l'État), compte tenu également de la connaissance des parties prenantes sur leurs droits. La discussion est basée sur une enquête menée entre les années 2010-2014, recouvrant les dimensions de procédure et substantielle de l'accès à la justice. Nous documentons de manière critique l'état de l'art de la mesure et de la construction des indicateurs de comportement de l'accès à la justice, notant les limitations rencontrées et les moyens de les contourner, en mettant l'accent sur la validité conceptuelle des mesures et sur les filtres utilisés dans la définition de ce qu'est l'accès à la justice. A partir de la mesure proposée, nous concluons que le phénomène mesuré est différent en fonction de l'importance que I'on donne, soit au conflit soit à la recherche des institutions, étant donné que les gens réagissent différemment aux différents types de situations potentiellement conflictuelles.

Mots-clés: accès à la justice; gestion des conflits; indicateurs subjectifs; dimension procédurale; dimension substantielle 